\title{
Clinical practice guideline for renal rehabilitation: systematic reviews and recommendations of exercise therapies in patients with kidney diseases
}

Kunihiro Yamagata ${ }^{1 *}$, Junichi Hoshino ${ }^{2}$, Hitoshi Sugiyama ${ }^{3}$, Norio Hanafusa ${ }^{4}$, Yugo Shibagaki $^{5}$, Yasuhiro Komatsu ${ }^{6}$, Tsuneo Konta ${ }^{7}$, Naohiko Fujii ${ }^{8}$, Eiichiro Kanda ${ }^{9}$, Tadashi Sofue ${ }^{10}$, Kiyonobu Ishizuka ${ }^{11}$, Masashi Kitagawa ${ }^{12}$, Keiji Kono ${ }^{13}$, Norikazu Hinamoto ${ }^{12}$, Takayuki Miyai ${ }^{14}$, Kiyomi Koike ${ }^{15}$, Susumu Toda ${ }^{16}$, Jumpei Hasegawa ${ }^{17}$, Masayuki Yamanouchi ${ }^{18}$, Ryuichi Yoshimura ${ }^{19}$, Ryota Ishii ${ }^{1}$, Shunsuke Goto ${ }^{13}$, Hiroo Kawarazaki ${ }^{20}$, Kentaro Takase ${ }^{19}$, Fumika Taki ${ }^{21}$, Mimiko Matsumura ${ }^{22}$, Yoshihiko Raita ${ }^{23}$, Satoko Sakurai ${ }^{24}$, Tatsuya Shimizu', Suguru Yamanoto ${ }^{25}$, Takehiko Kawaguchi ${ }^{26}$, Hideyo Oguchi ${ }^{27}$, Makoto Tsujita ${ }^{15}$, Masahiko Yazawa ${ }^{5}$, Akiko Uchida ${ }^{28}$, Yasuhiro Ando ${ }^{29}$, Satoru Kaneko ${ }^{30}$, Atsuhiko Matsunaga ${ }^{31}$, Taku Harada ${ }^{32}$, Osamu Ito $^{33}$ and Masahiro Kohzuki ${ }^{32}$

\begin{abstract}
In recent years, a concept of renal rehabilitation has become widely known among nephrology specialists, dialysis specialists, kidney transplantation specialists, rehabilitation specialists, nutrition specialists, guideline specialists, nurses, physiotherapists, and representatives of patients. Therefore, in order to make it clear the definition, methods, and effectiveness of renal rehabilitation in Japan, we launched Renal Rehabilitation Guideline Preparation Committee in 2016 as a part of works in the Japanese Society of Renal Rehabilitation, and created a guideline in accordance to the "Minds Handbook for Clinical Practice Guideline Development 2014". Here, we report systematic reviews and recommendations of exercise therapies in patients with kidney diseases based on the guideline preparation committee works. Six recommendations for the condition of each kidney disorder, groups addressing nephritis/nephrosis, chronic kidney diseases, dialysis therapy, and kidney transplantation were created. All the recommendation grades were determined by a consensus conference participated in by representatives of patients and various professionals. The purpose of this report is to provide an evidence-based, best practice summary to optimize the quality, safety and efficacy, and availability of renal rehabilitation service, and to provide care for maximum patient prognosis, quality of life, and satisfaction.
\end{abstract}

Keywords: Renal rehabilitation, Exercise therapy, CKD, Dialysis, Transplantation

\section{Introduction}

The management of primarily elderly chronic kidney disease (CKD) and dialysis patients is an urgent task in Japan. The number of patients with CKD has increased to 13.3 million, and that of patients receiving hemodialysis due to chronic renal failure surpassed 320,000 as of the end of 2015. The quality of dialysis therapy in Japan is

\footnotetext{
* Correspondence: k-yamaga@md.tsukuba.ac.jp

1 Department of Nephrology, Faculty of Medicine, University of Tsukuba,

1-1-1, Ten-oudai, Tsukuba, Ibaraki 305-8575, Japan

Full list of author information is available at the end of the article
}

leading the world, but while long-term survival for 40 years or longer has been achieved, aging of patients is progressing with the mean age at the introduction of dialysis being 69.2 years and the mean age of all dialysis patients being 67.9 years. The percentage of patients with multiple disabilities is also increasing.

CKD is not only a major risk factor for dialysis but also increases the risk of cardiovascular diseases and is closely related to lifestyle-related diseases such as diabetes and hypertension. In addition, dialysis patients develop complications including cardiovascular diseases, 
infections, and malignant neoplasms and have a very poor prognosis as the mortality 3 years after the initiation of dialysis exceeds $30 \%$.

Methods for the diagnosis and treatment of various underlying diseases that lead to CKD have been described in the literature including evidence-based guidelines. However, treatments for CKD itself, methods for coordination among medical professionals involved in the management of CKD, and, particularly, systematic organization of comprehensive treatments including methods for patient-centered care have been inadequate. Under such circumstances, the Japanese Society of Renal Rehabilitation was established in 2011. Rehabilitation is defined by the WHO to "include all means to alleviate the effects of conditions that may bring about disabilities and social disadvantages and achieve social integration of people with disabilities and social disadvantages." Therefore, renal rehabilitation was defined as "a long-term comprehensive program consisting of exercise therapy, diet therapy and water management, drug therapy, education, psychological/mental support, etc., to alleviate physical/mental effects based on kidney disease and dialysis therapy, prolong the life expectancy, and improve psychosocial and occupational circumstances." Thus, rehabilitation in its original form is to conduct all treatments and support to help all kidney disease patients smoothly achieve social rehabilitation instead of simply implementing exercise therapy.

\section{Background of preparation of this guideline}

Along with the steady development of the Japanese Society of Renal Rehabilitation, Renal Rehabilitation (written and edited by Masahiro Kohzuki) was published in 2012 (revised in 2018), "Guide for Renal Rehabilitation for Predialysis Stage Renal Failure" (prepared by the Japanese Society of Renal Rehabilitation) was presented on the website in 2016. Moreover, admitting the effectiveness of exercise guidance or advanced diabetic nephropathy, "additional fees for diabetes and dialysis prevention guidance and management and guidance for patients in the renal failure stage" were newly approved by the health insurance system of Japan in 2016. Through these events, the time has come to evaluate the preparation of a clinical practice guideline to clearly define renal rehabilitation as a medical action and to provide care for maximum patient prognosis, quality of life (QOL), and satisfaction. This guideline aims to optimize the quality, safety and efficacy, and availability of renal rehabilitation service. Among the items that constitute renal rehabilitation, exercise therapy, in particular, is the core of a comprehensive program, and the preparation of a practical manual for its implementation has been ardently awaited. Therefore, in this guideline, primarily evidence of exercise therapy for CKD patients, about which the literature is relatively rich, was reviewed. The procedure for the preparation of clinical practice guideline has markedly changed with time. In this guideline, also, we paid attention to matters including systematic review of evidence, preparation of recommendations intended to optimize patient care, use of quality indicators as guarantees for the quality of the guideline, and participation of patients in the preparation of the guideline based on the "Minds Handbook for Clinical Practice Guideline Development 2014".

\section{Preparation procedure}

The guideline preparation committee was organized with a wide range of knowledgeable persons including nephrology specialists, dialysis specialists, kidney transplantation specialists, rehabilitation specialists, nutrition specialists, guideline specialists, nurses, physiotherapists, and representatives of patients. A guideline supervising panel consisting of the chairman andtwo members of the executive board of our society was established, and the chairman of the guideline preparation committee was assigned as its chairman. The guideline preparation secretariat was organized to manage the progression of guideline preparation, liaison among the members, arrangement of meetings, etc.

This guideline was intended for patients with glomerulonephritis/nephrotic syndrome, those with CKD in the predialysis stage, those receiving hemodialysis, and renal transplant recipients.

Since it was necessary to prepare clinical questions (CQs) appropriate for the condition of each kidney disorder, groups addressing nephritis/nephrosis, CKD, dialysis therapy, and kidney transplantation were organized for the sections of specific discussion, and CQs were drafted in each group using methods including the Delphi method. In the process of selection of intervention, we focused exercise therapies-as a part of renal rehabilitation-because we felt that the evidences in nutritional, mental, and social supports associated with renal rehabilitation was not enough for our systematic review. The SR member team nominated by the leader of each group searched PubMed and Japana Centra Revuo Medicina. Search formulas were shared concerning exercise intervention but prepared independently by each group concerning the target patients. The evidence of each paper was evaluated through multiple steps according to the Minds Handbook: Primary evaluation was made independently by two or more members, secondary evaluation was made by a conference of group leaders and subleaders on the basis of the results of the primary evaluation, and final decisions were reached through discussion by the committee. Particularly, recommendation grades were determined by a consensus conference participated in by representatives of patients 
and various professionals. The details of recommendation grades were shown in the Table 1. The final draft was prepared through a peer review by two referees for each chapter, reviews by related scientific societies, and hearing of public comment.

\section{Renal rehabilitation for patients with nephritis/ nephrotic syndrome Introduction}

1. Objectives and expected effects

- The number of patients who begin to receive chronic dialysis therapy due to chronic glomerulonephritis including glomerulonephritis and nephrotic syndrome is decreasing progressively (an overview of regular dialysis treatment in Japan as of Dec. 31, 2016, Japanese Society for Dialysis Therapy).

- Meanwhile, immunoglobulin A (IgA) nephropathy, primary nephrotic syndrome, primary membranoproliferative glomerulonephritis, etc. were designated as intractable diseases in 2015, and their importance as rare diseases is increasing.

- It is considered significant to address comprehensive renal rehabilitation including exercise therapy as part of treatment from the viewpoint of providing high-quality and appropriate medical care to adults and children with glomerulonephritis or nephrotic syndrome.

- The quality of life of adults and children with glomerulonephritis or nephrotic syndrome is expected to be improved by adopting aggressive exercise therapy appropriate for the disease stage, e.g., the stable period of glomerulonephritis and remission period of nephrotic syndrome.

2. Lifestyle modification, dietary counseling, and medications

- Lifestyle and dietary guidance are the basis for renal rehabilitation for adults and children with glomerulonephritis and nephrotic syndrome.

Table 1 Summary of the strength of recommendation and evidence

Strength of recommendation

1 Strongly recommended

2 Weakly recommended (suggested)

Strength of evidence (the overall strength of evidence across outcomes)

A Strongly confident of the estimate of effect (strong)

B Moderately confident of the estimate of effect (moderate)

C Limited confidence of the estimate of effect (weak)

$D$ Very little confident of the estimate of effect (very weak)
- In drug therapy, drugs including corticosteroid (steroid) and immunosuppressants are used. It should be noted that the doses are adjusted according to the condition of each patient (increased, reduced, or discontinued).

- In patients being treated with steroid or immunosuppressants, attention to prevention of infection is necessary in lifestyle guidance. Preventive vaccination (influenza vaccine, pneumococcal vaccine, etc.) should be considered as necessary. In patients treated with oral steroid for 3 months or longer, the fracture risk should be evaluated, and measures to control it should be taken. Attention to necrosis of the femoral head is necessary after steroid pulse therapy.

- In conducting dietary guidance, the Dietary Recommendations for Chronic Kidney Disease, 2014 (adults and children, edited by the Japanese Society of Nephrology, Tokyo Igakusha) should be consulted. It is important to provide dietary guidance appropriate for the disease stage concerning restriction of salt intake and protein and energy intake. In elderly patients, caution to avoid malnutrition is necessary.

- Concerning individual diseases, the evidencebased clinical practice guidelines for IgA nephropathy 2017 (edited by the Study Group on Intractable Kidney Diseases, Tokyo Igakusha) and evidence-based clinical practice guidelines for nephrotic syndrome 2017 (edited by the Study Group on Intractable Kidney Diseases, Tokyo Igakusha) are recommended as references.

- Regarding lifestyle/dietary guidance and treatment for children with nephrotic syndrome, consult the clinical practice guidelines for pediatric idiopathic nephrotic syndrome 2013 (edited by the Japanese Society for Pediatric Nephrology, Shindantochiryosha).

3. Positions of exercise therapy

- Exercise therapy for adults and children with glomerulonephritis or nephrotic syndrome has been discussed primarily regarding the necessity of rest and exercise restriction.

- Presently, therefore, there is no systematic evidence positively recommending or supporting the usefulness of exercise therapy.

- For the future, appropriate exercise restriction in the acute and unstable periods of the disease, in the remission induction period of drug therapy, and for the prevention of recurrence, avoidance of excessive exercise restriction, and exercise prescriptions in the stable and remission periods as well as methods for their assessment should be established. 
CQ1 Can exercise restriction be recommended for patients with glomerulonephritis?

[Recommendation]

Exercise restriction is proposed not to be applied to patients with glomerulonephritis. [2D]

[Comments]

The effects of exercise therapy on patients with glomerulonephritis were evaluated from the viewpoints of four outcomes: survival rate, QOL, decline of renal function, and increase in urinary protein.

For systematic review, PubMed and Japana Centra Revuo Medicina were searched using the search formulas shown elsewhere, and 3960 papers were retrieved. Through primary screening according to the title and abstract and secondary screening according to the text, six papers were eventually selected to be evaluated. Since they included no randomized controlled trial (RCT), and since many of them were published before 2000 and had bias risks and missing values, quantitative evaluation was judged to be difficult, and qualitative systematic review was carried out. In young adult patients diagnosed by renal biopsy to have chronic glomerulonephritis with normal renal function and moderate proteinuria (0.8-1.5 g/day) (IgA nephropathy, ten patients), urinary protein was reported to have increased temporarily after exercise stress but to have returned to the original level $2 \mathrm{~h}$ after the end of exercise [1]. The urinary protein level corrected for the glomerular filtration rate (GFR) increased by $65.9 \% 1 \mathrm{~h}$ after the 25 -min Bruce maximal treadmill test but decreased to the resting level after $2 \mathrm{~h}$, when the renal function increased by $7.1 \%$.

When the maximum oxygen uptake (peak $\mathrm{VO}_{2}$ ) was measured on the bicycle ergometer stress exercise test in patients with chronic glomerulonephritis definitively diagnosed by renal biopsy ( 69 patients aged $11-67$ years, 44 males and 25 females), the peak $\mathrm{VO}_{2}$ decreased with the duration of illness, decreases in the blood hemoglobin level, increases in urinary protein, and decline of renal function. The peak $\mathrm{VO}_{2}$ was significantly higher in those with a higher daily activity level than in the less active group [2]. A decline of the whole-body endurance capacity may be induced by a decrease in daily activity level and prolongation of the duration of illness as well as deterioration of the renal function and anemia.

Although it is necessary to individually evaluate the age and degrees of proteinuria and impairment of renal function, there is no clear evidence that the prognosis of glomerulonephritis is exacerbated by exercise or that the prognosis is improved by rest and exercise restriction. Therefore, we propose not to uniformly apply exercise restriction to patients with glomerulonephritis.

Also, there have been few reports on exercise loading in patients who show marked proteinuria or a rapid decrease in renal function in a short period. In addition, the exercise stress level or exercise prescription tolerated in the stable period or the effects of intense exercise stress have not been clarified. For patients with glomerulonephritis, it is important to evaluate indications and intensity of exercise therapy individually and according to the disease stage with observation of the clinical course rather than uniformly judge its applicability.

CQ2 Can rest/exercise restriction be recommended for nephrotic syndrome?

[Recommendation]

Excessive rest or exercise restriction is proposed not to be applied to patients showing nephrotic syndrome. [2D]

[Comments]

The effects of exercise therapy in patients with nephrotic syndrome were evaluated from the viewpoint of four outcomes: survival rate, QOL, decline in renal function, and increase in urinary protein.

For systematic review, PubMed and Japana Centra Revuo Medicina were searched using the search formulas shown elsewhere, and 3960 papers were retrieved. Through primary screening according to the title and abstract and secondary screening according to the text, three papers were eventually selected to be evaluated. Since there was no randomized controlled trial (RCT), many reports were published before 2000, and there were many bias risks and missing values, quantitative evaluation was judged to be difficult, and qualitative systematic review was conducted.

When patients with minimal change nephrotic syndrome (MCNS) in the remission period (six patients aged 10-19 years) were examined by the bicycle ergometer exercise stress test ( $70 \%$ of maximum exertion), the decrease in glomerular filtration rate (GFR), decrease in renal plasma flow, and increase in filtration rate observed during exercise recovered to the pre-exercise level after $60 \mathrm{~min}$ similarly to healthy individuals (seven subjects). The increase in albumin in urine after exercise showed no significant difference compared with healthy subjects [3].

There is no clinical evidence that supports exercise restriction in patients with nephrotic syndrome in remission. Since there is no report that directly examined the effects of rest and exercise restriction, the effects of rest and exercise restriction in patients showing nephrotic syndrome are unclear. Therefore, we propose to avoid instructing excessive rest or uniform exercise restriction.

During the administration of a low dose of steroid as maintenance therapy in the remission period, appropriate exercise therapy is considered necessary from the viewpoint of prevention of obesity and steroid-induced osteoporosis. However, it has been reported that the plasma creatine kinase level increased significantly in patients with nephrotic syndrome without renal failure 
(14 patients) compared with healthy subjects $1 \mathrm{~h}$ after a bicycle ergometer exercise stress test (70\% of maximum loading) [4], suggesting some metabolic changes in skeletal muscle cells.

\section{Renal rehabilitation for patients with non-dialysis- dependent CKD Introduction}

1. Objectives and expected effects

- In CKD patients, the physical function is reduced to about $70 \%$ compared with healthy individuals [5-7].

- CKD patients often develop various complications including cardiovascular disease, renal anemia [8], reduced bone strength [9], and neuropathy [10]. All these complications directly lead to a decline in physical function, and rehabilitation is expected to have multiple beneficial effects on them.

- CKD patients are likely to develop a condition called protein-energy wasting (PEW), in which body protein mass is reduced by protein catabolism, etc. Also, the endurance capacity is reduced due to mitochondrial dysfunction [11, 12]. Such abnormal muscle metabolism associated with CKD may be improved by renal rehabilitation.

- The present systematic review is expected to lead to future improvements in the health of CKD patients by clarifying the evidence at present and promoting understanding of unresolved problems.

2. Lifestyle modification, dietary counseling, and medications

- For renal rehabilitation of CKD patients, multifaceted lifestyle guidance including nutritional management and psychosocial care for improvement of health status is important in addition to exercise therapy [13].

- For nutritional management of CKD patients, control high energy (30-35 kcal $/ \mathrm{kg} /$ day), low protein $(0.6-0.8 \mathrm{~g} / \mathrm{kg} /$ day), and low salt (3-6 g/day) diet is the basic recommendation, which may be modified taking into account of the individual's health condition. For details, refer to the Dietary Recommendations for Chronic Kidney Disease, 2014 (edited by the Japanese Society of Nephrology, Tokyo Igakusha).

- With the increase in older patients, malnutrition has emerged as a problem of CKD patients. Appropriate dietary guidance with a dietician is important for the prevention of malnutrition.

- Concerning lifestyle, see the Evidence-based Clinical Practice Guidelines for CKD 2018
(Japanese Society of Nephrology) and Manual for Lifestyle and Dietary Guidance for CKD for Physicians and Co-medicals.

3. Positions of exercise therapy

- There used to be an opinion-based recommendation for the restriction of physical activity in patients with renal insufficiency; however, many recent guidelines including those by the Japanese Society of Nephrology, Kidney Disease: Improving Global Outcomes (KDIGO), and National Rehabilitation Association emphasize comprehensive, favorable effects of exercise therapy on the health status, such as improvements in activity of daily living (ADL), cardiovascular function, and psychosocial conditions, and recommend moderate exercise therapy for patients with stable CKD $[14,15]$.

- The Clinical Practice Guidelines for CKD 2009 published by the Japanese Society of Nephrology recommended regular exercise as far as physical conditions and comorbidities were tolerable, because there had been no evidence that moderate exercise without fatigue in CKD patients (about 5 METs) should exacerbate kidney function unless otherwise being stable.

- However, the revised version of the Clinical Practice Guidelines for CKD 2013, which only valued high-quality evidences, stated conservatively, "Whether exercise affects the progression of CKD is unclear."

- On the other hand, the guidelines issued by the American College of Sports Medicine (ACSM) in 2014 recommended starting exercise intervention in CKD patients with a mild to moderate intensity, monitoring and titrating the exercise intensity according to the patient's physical capacity (ACSM, Guidelines for Exercise Testing and Prescription Ninth Edition).

- Thus, the clinical relevance of exercise therapy in CKD patients has not been established and must be updated through the accumulation of evidences.

- The practical, optimal intervention method of exercise therapy for individual patients should be discussed in the future.

- Building the instruction method and the selfsupporting system for sustainable exercise intervention is also an important theme for the future.

CQ3 Is exercise therapy recommended for patients with non-dialysis-dependent CKD?

[Recommendation]

Moderate exercise therapy is recommended for patients with non-dialysis-dependent CKD in consideration of their age and physical function. [2C] 


\section{[Comments]}

The effect of exercise therapy in patients with non-dialysis-dependent CKD was evaluated from the viewpoints of five outcomes: death, renal outcome, hospitalization, exercise tolerance, and QOL.

We searched records of published literature related to renal rehabilitation in PubMed and Japana Centra Revuo Medicina using the corresponding search formulas described below. After the initial search, 3582 records were retrieved from PubMed, and 823 from Japana Centra Revuo Medicina. We performed the primary screening by title and abstract, leaving 186 and 54 papers in PubMed and Japana Centra Revuo Medicina, respectively. Then, the secondary screening was done by overviewing the contents of the text, and 50 papers were eventually selected for the further full-text evaluation.

\section{Death}

There was no RCT reporting death as a primary outcome. Although four RCTs reported death as an adverse event [16-19], the statistical analysis was not available due to a limited observation period and an insufficient number of subjects or events.

\section{Renal outcome}

Regarding the renal outcome, nine RCTs were analyzed [20-28]; one paper evaluated the time to renal replacement therapy or death as a primary endpoint [20], one estimated the incidence rate of very-high-risk CKD based on the heat map of the KDIGO 2013 classification [21], and the others compared changes in eGFR [22-28]. In the report that evaluated the hard outcome (a composite of renal replacement therapy and death) [20], no significant difference was observed; however, the results may not have simply reflected the effect of exercise therapy, because the outcome was investigated 20 or more years after the therapeutic intervention. According to the study that evaluated the prognostic risk on the heat map as a surrogate marker [21], the therapeutic intervention significantly reduced the risk of developing very-high-risk CKD (odds ratio 0.69 [0.55-0.87]). But it remains unclear whether similar results can be obtained by exercise therapy alone, because the intervention was an intensive lifestyle modification with a combination of constant weight loss and increased physical activity. Besides, the study subjects included some CKD patients, but the main target was obese patients with type 2 diabetes. A careful interpretation is required when we extrapolate these findings to CKD patients.

In a meta-analysis of seven studies that compared changes in eGFR [22-28], a significant improvement of $+2.22\left([0.68-3.76] \mathrm{mL} / \mathrm{min} / 1.73 \mathrm{~m}^{2}: I^{2}=18 \%\right)$ was observed by the exercise intervention for 12-24 weeks (Fig. 1). However, due to a limited number of the subjects in the meta-analysis (81 treated subjects and 84 controls), it is considered premature to conclude that exercise therapy is effective, considering the difference in the characteristics of the subjects and intervention methods.

Most studies included in this review were designed to include diabetic, obese patients with mild renal insufficiency. There was one small-scale pilot study, in which aerobic exercise therapy was administered three times a week for 12 months to non-diabetic CKD patients at stages G3-4 with progressive renal impairment [24], reporting that the eGFR, which was once lower in the exercise group at baseline, improved after intervention and eventually became comparable to that in the control group. The study demonstrated a significant eGFR increase by $7.8 \pm 3.0 \mathrm{~mL} / \mathrm{min} / 1.73 \mathrm{~m}^{2}(p=0.02)$ at 12 months in the exercise group compared with the control group, suggesting possible improvement in renal function by exercise therapy even in CKD patients without diabetes or obesity. Validation in a large-scale study is warranted.

\section{Hospitalization}

There was no paper reporting hospitalization as an outcome. Thus, the evaluation for hospitalization was unavailable in the current guideline.

\section{Exercise tolerance}

Fourteen RCTs [16-19, 23-25, 27, 28, 30-34] and two prospective interventional studies $[35,36]$ were included in the systematic review for the improvement in exercise tolerance [29]. The intervention method varied from paper to paper; resistance training in four studies [17, $18,24,34]$, intermittent exercise therapy in four studies $[19,31,33,36]$, and aerobic exercise therapy or low-intensity exercise therapy in the others. There were two studies that included lifestyle modification in the intervention arm [16, 34].

The $\mathrm{VO}_{2}$ peak was examined as an outcome in nine RCTs [23, 24, 27, 28, 30-34], and improvements were observed in most studies despite differences in the intervention method. For the meta-analysis, we performed the pairwise evaluation using the reported figures before and after intervention in three studies [30, 32, 34]. In the remaining six studies [23, 24, 27, 28, 31, 33], the values after intervention were compared. By meta-analysis, heterogeneity was observed, but a significant overall improvement of $+3.23[1.45-5.02] \mathrm{mL} / \mathrm{kg} / \mathrm{min}\left(I^{2}=67 \%\right)$ was observed as a whole (Fig. 2). This suggests that exercise therapy significantly improves the $\mathrm{VO}_{2}$ peak also in CKD patients. 


\begin{tabular}{|c|c|c|c|c|c|c|c|c|c|}
\hline \multirow[b]{2}{*}{ Study or Subgroup } & \multicolumn{3}{|c|}{ Exercise } & \multicolumn{3}{|c|}{ Control } & \multirow[b]{2}{*}{ Weight } & \multirow{2}{*}{$\begin{array}{l}\text { Mean Difference } \\
\text { IV, Random, } 95 \% \mathrm{Cl}\end{array}$} & \multirow{2}{*}{$\begin{array}{l}\text { Mean Difference } \\
\text { IV, Random, } 95 \% \mathrm{Cl}\end{array}$} \\
\hline & Mean & SD & Total & Mean & SD & Total & & & \\
\hline \multicolumn{10}{|l|}{1 Paired } \\
\hline Greenwood, AJKD 2011 [20] & -3.8 & 2.8 & 8 & -8.5 & 6.4 & 10 & $10.3 \%$ & $4.70[0.28,9.12]$ & $\longrightarrow$ \\
\hline Leehey, Am J Nephrol 2016 [24] & -2 & 5.8 & 14 & -3.1 & 6 & 18 & $11.6 \%$ & $1.10[-3.01,5.21]$ & 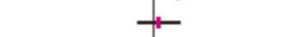 \\
\hline Eidemak, Nephron 1997 [18] & -5.336 & 6.518 & 15 & -3.824 & 3.764 & 15 & $13.2 \%$ & $-1.51[-5.32,2.30]$ & 4 \\
\hline Straznicky, J Hypertens 2011 [21] & 6.6 & 0.8 & 13 & 4 & 1 & 13 & $59.6 \%$ & $2.60[1.90,3.30]$ & n \\
\hline Subtotal $(95 \% \mathrm{Cl})$ & & & 50 & & & 56 & $94.6 \%$ & $1.90[-0.15,3.95]$ & \\
\hline \multicolumn{10}{|l|}{$\begin{array}{l}\text { Heterogeneity: } \text { Tau }^{2}=2.10 ; \text { Chi }^{2}=5.74 \\
d f=3(P=0.13) ; I^{2}=48 \%\end{array}$} \\
\hline \multicolumn{10}{|l|}{ Test for overall effect: $Z=1.82 \quad(P=0.07)$} \\
\hline \multicolumn{10}{|l|}{2 Unpaired } \\
\hline Leehey, Cardiovasc Diabetology 2009 [22] & 39 & 22 & 7 & 41 & 5.3 & 4 & $0.8 \%$ & $-2.00[-19.11,15.11]$ & \\
\hline Baria, NDT 2014 [23] & 29.4 & 8.7 & 10 & 25.9 & 14 & 9 & $2.0 \%$ & $3.50[-7.12,14.12]$ & \\
\hline Aoike, Int Urol Nephrol 2015 [19] & 31.9 & 13.7 & 14 & 23.9 & 12.2 & 15 & $2.5 \%$ & $8.00[-1.47,17.47]$ & \\
\hline Subtotal $(95 \% \mathrm{Cl})$ & & & 31 & & & 28 & $5.4 \%$ & $4.84[-1.69,11.37]$ & \\
\hline \multicolumn{10}{|l|}{$\begin{array}{l}\text { Heterogeneity: } \text { Tau }^{2}=0.00 ; \mathrm{Chi}^{2}=1.10 \\
\quad \mathrm{df}=2(P=0.58) ; \mathrm{I}^{2}=0 \%\end{array}$} \\
\hline \multicolumn{10}{|l|}{ Test for overall effect: $Z=1.45 \quad(P=0.15)$} \\
\hline \multirow{2}{*}{$\begin{array}{l}\text { Total }(95 \% \mathrm{Cl}) \\
\text { Heterogeneity: } \text { Tau }^{2}=0.91 ; \mathrm{Chi}^{2}=7.34 \text {, } \\
\quad \text { df }=6(P=0.29) ; I^{2}=18 \%\end{array}$} & & & 81 & & & 84 & $100.0 \%$ & $2.22[0.68,3.76]$ & $\checkmark$ \\
\hline & & & & & & & & & 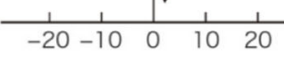 \\
\hline \multirow{2}{*}{\multicolumn{9}{|c|}{$\begin{array}{l}\text { Test for overall effect: } Z=2.83 \quad(P=0.005) \\
\text { Test for subgroup differences: }\end{array}$}} & Favours \\
\hline & & & & & & & & & [Exercise] \\
\hline \multicolumn{10}{|l|}{ Chiz $=0.71, d f=1 \quad(P=0.40), i z=0 \%$} \\
\hline
\end{tabular}

There have also been five RCTs that evaluated the 6-min walking distance as an outcome [16, 19, 23, 27, 28], one pair analysis according to the change between before and after intervention [19], and four papers that compared the value after intervention $[16,23,27,28]$. As a result of meta-analysis, a significant improvement in the walking distance of $+51.3[22.2-80.4] \mathrm{m}\left(I^{2}=27 \%\right)$ was obtained in the exercise group. This suggests that exercise intervention significantly increases the 6-min walking distance (Fig. 3).

All evidence concerning exercise tolerance had a small sample size and varied in intervention method, but improvements were observed in many reports, and the results of meta-analysis are considered to guarantee some degree of reliability. However, since the 6-min walking distance is likely to be affected by the subjectivity of

\begin{tabular}{|c|c|c|c|c|c|c|c|c|c|c|c|}
\hline \multirow[b]{2}{*}{ Study or Subgroup } & \multicolumn{3}{|c|}{ Exercise } & \multicolumn{3}{|c|}{ Control } & \multirow[b]{2}{*}{ Weight } & \multirow{2}{*}{$\begin{array}{l}\text { Mean Difference } \\
\text { IV, Random, } 95 \% \mathrm{Cl}\end{array}$} & \multirow{2}{*}{\multicolumn{3}{|c|}{$\begin{array}{l}\text { Mean Difference } \\
\text { IV, Random, } 95 \% \mathrm{Cl}\end{array}$}} \\
\hline & Mean & $\mathrm{SD}$ & Total & Mean & $\mathrm{SD}$ & Total & & & & & \\
\hline \multicolumn{12}{|l|}{1 Paired } \\
\hline Mustata, Int Urol Nephrol 2011 [25] & 3.2 & 3 & 10 & -0.6 & 2.4 & 10 & $13.7 \%$ & $3.80[1.42,6.18]$ & & . & \\
\hline Van Craenenbroeck, AJKD 2015 [27] & 5.8 & 3.6 & 19 & -0.8 & 3.4 & 21 & $14.3 \%$ & $6.60[4.42,8.78]$ & & $\longrightarrow$ & \\
\hline Howden, CJASN 2013 [5501] & 2.8 & 4.3 & 36 & -0.4 & 4.9 & 36 & $14.4 \%$ & $3.20[1.07,5.33]$ & & $\longrightarrow$ & \\
\hline Subtotal $(95 \% \mathrm{Cl})$ & & & 65 & & & 67 & $42.4 \%$ & $4.54[2.44,6.64]$ & & & \\
\hline \multicolumn{12}{|c|}{ Heterogeneity: $\mathrm{Tau}^{2}=2.15 ; \mathrm{Chi}^{2}=5.33, \mathrm{df}=2(\mathrm{P}=0.07) ; \mathrm{I}^{2}=63 \%$} \\
\hline \multicolumn{12}{|c|}{ Test for overall effect: $Z=4.24(P<0.0001)$} \\
\hline \multicolumn{12}{|l|}{2 Unpaired } \\
\hline Aoike, Int Urol Nephrol 2015 [19] & 26.1 & 7 & 14 & 24.2 & 7.1 & 15 & $7.2 \%$ & $1.90[-3.23,7.03]$ & & & \\
\hline Baria, NDT 2014 [23] & 27.8 & 6.2 & 10 & 27.1 & 5.2 & 9 & $7.2 \%$ & $0.70[-4.43,5.83]$ & & & \\
\hline Greenwood, AJKD 2011 [20] & 23 & 5.3 & 8 & 16.2 & 5 & 10 & $7.8 \%$ & $6.80[1.99,11.61]$ & & & \\
\hline Headley, AJKD 2014 [28] & 21.2 & 7.7 & 25 & 17.5 & 5.7 & 21 & $9.8 \%$ & $3.70[-0.18,7.58]$ & & & \\
\hline Headley, Med \& Sciin Sports \& Ex 2012 [26] & 19.5 & 4.6 & 10 & 17 & 3.1 & 10 & $10.8 \%$ & $2.50[-0.94,5.94]$ & & & \\
\hline Leehey, Am J Nephrol 2016 [24] & 12.4 & 2.7 & 14 & 12.7 & 3.2 & 18 & $14.7 \%$ & $-0.30[-2.35,1.75]$ & & & \\
\hline Subtotal $(95 \% \mathrm{Cl})$ & & & 81 & & & 83 & $57.6 \%$ & $2.19[0.07,4.30]$ & & & \\
\hline \multicolumn{12}{|c|}{$\begin{array}{l}\text { Heterogeneity: } \mathrm{Tau}^{2}=3.08 ; \mathrm{Chi}^{2}=9.32, \mathrm{df}=5 \quad(P=0.10) ;\left.\right|^{2}=46 \% \\
\text { Test for overall effect: } Z=2.02(P=0.04)\end{array}$} \\
\hline Total $(95 \% \mathrm{Cl})$ & & & 146 & & & 150 & $100.0 \%$ & $3.23[1.45,5.02]$ & & & \\
\hline $\begin{array}{l}\text { Heterogeneity; } \mathrm{Tau}^{2}=4.54 ; \mathrm{Chi}^{2}=24.40 \text {, } \\
\qquad \mathrm{df}=8 \quad(P=0.002) \cdot \mathrm{l}^{2}=67 \%\end{array}$ & & & & & & & & $\frac{1}{-10}$ & $\frac{1}{-5}$ & $\frac{1}{5}$ & $\frac{1}{10}$ \\
\hline Test for overall effect; $Z=3.56(P=0.0004)$ & & & & & & & & & Favours & Favours & \\
\hline $\begin{array}{l}\text { Test for subgroup differences: } \mathrm{Chi}^{2}=2.40 \text {, } \\
\quad \mathrm{df}=1 \quad(\mathrm{P}=0.12), \mathrm{I}^{2}=58.3 \%\end{array}$ & & & & & & & & & [Control] & [Exercise] & \\
\hline
\end{tabular}




\begin{tabular}{|c|c|c|c|c|c|c|c|c|c|c|}
\hline \multirow[b]{2}{*}{ Study or Subgroup } & \multicolumn{3}{|c|}{ Exercise } & \multicolumn{3}{|c|}{ Control } & \multirow[b]{2}{*}{ Weight } & \multirow{2}{*}{$\begin{array}{l}\text { Mean Difference } \\
\text { IV, Random, } 95 \% \mathrm{Cl}\end{array}$} & \multirow{2}{*}{\multicolumn{2}{|c|}{$\begin{array}{l}\text { Mean Difference } \\
\text { IV, Random, } 95 \% \mathrm{Cl}\end{array}$}} \\
\hline & Mean & SD & Total & Mean & SD & Total & & & & \\
\hline \multicolumn{11}{|l|}{1 Paired } \\
\hline Rossi, CJASN 2014 [15] & 64.1 & 81.1 & 48 & -3 & 67 & 46 & $41.0 \%$ & $67.10[37.08,97.12]$ & & 上 \\
\hline Subtotal $(95 \% \mathrm{Cl})$ & & & 48 & & & 46 & $41.0 \%$ & $67.10[37.08,97.12]$ & & \\
\hline \multicolumn{11}{|l|}{ Heterogeneity: Not applicable } \\
\hline \multicolumn{11}{|l|}{ Test for overall effect: $Z=4.38 \quad(P<0.0001)$} \\
\hline \multicolumn{11}{|l|}{2 Unpaired } \\
\hline Aoike, Int Urol Nephrol 2015 [19] & 583.1 & 85.2 & 14 & 561.2 & 91.2 & 15 & $16.0 \%$ & $21.90[-42.30,86.10]$ & & \\
\hline Bria, NDT 2014 [23] & 662.8 & 88.4 & 10 & 592 & 85.5 & 9 & $11.6 \%$ & $70.80[-7.44,149.04]$ & & \\
\hline Howden, AJKD 2015 [12] & 539 & 82 & 32 & 472 & 129 & 35 & $22.3 \%$ & $67.00[15.68,118.32]$ & & \\
\hline Leehey, Am J Nephrol 2016 [24] & 394 & 139 & 14 & 425 & 115 & 18 & $9.1 \%$ & $-31.00[-121.13,59.13]$ & & \\
\hline Subtotal $(95 \% \mathrm{Cl})$ & & & 70 & & & 77 & $59.0 \%$ & $39.34[-1.71,80.38]$ & & $<$ \\
\hline \multicolumn{11}{|l|}{$\begin{array}{l}\text { Heterogeneity: } \text { Tau }^{2}=540.76 ; \mathrm{Chi}^{2}=4.33 \\
\qquad \mathrm{df}=3(\mathrm{P}=0.23) ;\left.\right|^{2}=31 \%\end{array}$} \\
\hline \multicolumn{11}{|l|}{ Test for overall effect: $Z=1.88 \quad(P=0.06)$} \\
\hline \multirow{5}{*}{$\begin{array}{l}\text { Heterogeneity: } \text { Tau }^{2}=303.78 ; \mathrm{Chi}^{2}=5.50, \\
\text { df=4 }(P=0.24) ;\left.\right|^{2}=27 \% \\
\text { Test for overall effect: } Z=3.46 \quad(P=0.0005) \\
\text { Test for subgroup differences: } \mathrm{Chi}^{2}=1.14 \text {, } \\
\text { df }=1 \quad(P=0.28), I^{2}=12.6 \%\end{array}$} & & & 118 & & & 123 & $100.0 \%$ & $51.32[22.22,80.43]$ & & \\
\hline & & & & & & & & & $\frac{1}{-100-50}$ & $0 \quad 100200$ \\
\hline & & & & & & & & & Favours & Favours \\
\hline & & & & & & & & & [Control] & [Exercise] \\
\hline & & & & & & & & $n-$ & & \\
\hline $\begin{array}{l}\text { Fig. } 3 \text { Forest plot of the effects of exercis } \\
\text { (reference [29]) }\end{array}$ & se interv & vention & on & hanges & in $6-m$ & in walk & king $d$ & ce for non-dialysis-d & ident CKD pa & patien \\
\hline
\end{tabular}

patients and does not have satisfactory reproducibility, it has been reported not to be optimal as a test of exercise tolerance, and validation using indices other than the above 2 is considered necessary for the future.

Concerning the QOL, there have been three papers using the SF-36 (including the RAND-36) as an evaluation index [19, 30, 33], one using the KDQOL [32], and two using original indices for the evaluation. Regarding physical function domains of the SF-36, meta-analysis indicated significant improvements in QOL in many domains related to fitness (Table 2).

Presently, there has not been a report of evaluation by the stage of CKD, and whether the effects of exercise therapy differ in stage 3-5 CKD is unknown.

As observed above, exercise therapy in predialysis patients with CKD is suggested to improve or maintain

Table 2 Effects of exercise intervention on changes in quality of life for non-dialysis-dependent CKD patients (meta-analysis)

\begin{tabular}{lll}
\hline SF-36 domains & $\begin{array}{l}\text { Mean changes } \\
\text { of the score }\end{array}$ & $p$ value \\
\hline Role physical & $+23.8[12.5 \sim 35.0]$ & $<0.01$ \\
Physical functioning & $+11.7[5.3 \sim 18.0]$ & $<0.01$ \\
Vitality (energy fatigue) & $+8.5[3.2 \sim 13.9]$ & $<0.01$ \\
General health & $+4.4[-0.3 \sim 9.1]$ & 0.07 \\
Bodily pain & $+7.7[1.1 \sim 26.1]$ & 0.02 \\
Mental health & $+4.7[0.0 \sim 9.4]$ & 0.05 \\
(emotional well-being) & & \\
Social functioning & $+1.8[-4.2 \sim 7.7]$ & 0.56 \\
Role emotional & $+5.5[-4.2 \sim 15.1]$ & 0.27 \\
\hline
\end{tabular}

SF36, the 36-item Short Form health Survey exercise tolerance and improve the QOL related to physical functions. However, there is presently no solid evidence that exercise therapy improves the vital prognosis or renal outcome.

In conclusion, there is no evidence that exercise therapy improves the vital prognosis, renal prognosis, or risk of hospitalization, but since it may improve or maintain exercise tolerance or the QOL related to physical functions, its applicability should be evaluated individually according to age and physical function, but we propose that (aerobic) exercise tolerated by the patient be performed (2C). Although the recommendation grade of exercise therapy was 1D in the KDIGO Guideline 2012, the evidence level was changed to $C$ in the present guideline, because there has been no decisive report leading to an important outcome despite an increase in evidence. The recommendation grade was kept as 2, because obesity is less frequent in Japanese CKD patients compared with patients in Western countries, and the impact of weight control by regular exercise is considered smaller.

\section{Renal rehabilitation for patients on hemodialysis Introduction}

1. Objectives and expected effects

Dialysis therapy is a treatment for end-stage renal disease presently applied to about 330,000 patients in Japan. Dialysis therapy can be either hemodialysis or peritoneal dialysis, but $97 \%$ of patients in Japan are receiving hemodialysis. At the end of 2015, the mean age of patients on dialysis was 67.9 years, and a prominent 
epidemiological characteristic of dialysis patients is an old age [37]. With aging of dialysis patients, frail patients are increasing. Frailty is not only related to a poor prognosis but may also be related to a decline in physical activity and exacerbation of the quality of life (QOL) [38, 39]. However, frailty is essentially a reversible condition and may be reversed toward normal by appropriate intervention. Improvements in the prognosis, exercise tolerance, QOL, and ADL may be expected by preventing and controlling the progression of frailty by renal rehabilitation.

2. Lifestyle modification, dietary counseling, and medications

PEW, which is closely related to frailty, is a condition in which malnutrition and wasting are observed simultaneously. Therefore, nutritional therapy as a treatment for malnutrition plays an important role in the management of PEW and frailty. Many observational studies have shown that an increase in the normalized protein catabolic rate (nPCR), which is an estimate of protein intake, is correlated with not only high albumin level and creatinine production rate, which are indices of PEW, but also a better survival [40]. In addition, catabolism may be suppressed, possibly leading to improvement in nutrition and reversal of wasting, by maintaining the energy intake [41]. Thus, nutritional therapy with securing the protein intake and energy intake is indispensable for patients showing malnutrition and wasting. The Dietary Recommendations for Chronic Dialysis Patients published by the Japanese Society for Dialysis Therapy 2014 also recommend an energy intake of $30-35 \mathrm{kcal} / \mathrm{kg}$ and protein intake of $0.9-1.2 \mathrm{~g} / \mathrm{kg}$ [42]. However, a study demonstrated that the physical function and QOL were significantly improved in patients with PEW by a combination of nutritional and exercise therapies compared with nutritional therapy alone [43], thus nutritional and exercise therapies are complementary to each other.

Securing of a sufficient dose of dialysis is also important. The results of post-hoc analysis of the HEMO study [44], which evaluated the relationship between the dose of dialysis and prognosis, and the Frequent Hemodialysis Network trial [45], which evaluated the effect of daily dialysis, showed associations of a sufficient dose of dialysis with better physical composite scores of the SF-36 and RAND-36. Such favorable physical QOL scores may have a benefit in rehabilitation. The Guidelines for Maintenance Hemodialysis: Hemodialysis Prescriptions by the Japanese Society of Dialysis Therapy recommend an $\mathrm{spKt} / \mathrm{V}$ of $\geq 1.4$ concerning small-molecule compounds and a $\beta_{2}$-microglobulin level of $<30 \mathrm{mg} / \mathrm{L}$ to be achieved [46].

In addition, the management of anemia is also important. While these are the results of observational studies, there has been a report that an increase in $\mathrm{Hb}$ due to change in the type of ESA led to an improvement in the vitality score of QOL [47] and a meta-analysis demonstrated that an improvement in $\mathrm{Hb}$ by ESA from $\mathrm{Hb}<10 \mathrm{~g} / \mathrm{dL}$ to $\geq 10 \mathrm{~g} / \mathrm{dL}$ was associated with a significant alleviation of malaise [48]. Both of these improvements in vitality and malaise may be beneficial for conducting exercise therapy. The 2015 Japanese Society for Dialysis Therapy: Guidelines for Renal Anemia in Chronic Kidney Disease recommend $\mathrm{Hb} \geq 10 \mathrm{~g} / \mathrm{dL}$ and $<12 \mathrm{~g} / \mathrm{dL}$ as a target $\mathrm{Hb}$ level in hemodialysis patients [49].

\section{Positions of exercise therapy}

The physical activity level has been reported to be reduced in dialysis patients, because dialysis patients tend to have sedentary lifestyle on the day of dialysis probably due to inactivity for the dialysis procedure and the post-dialysis fatigue syndrome [50]. In consequence, the physical function of elderly dialysis patients is reportedly about half that of the general population [51]. Moreover, a possible relationship of exercise with a favorable prognosis has also been suggested by an observational study [52]. On the basis of these reports, maintenance of the physical activity level and exercise therapy are attracting attention as measures to improve or maintain the survival, physical functions, ADL, and QOL. Among overseas reports, the Exercise \& Sports Science Australia issued a position statement concerning exercise therapy for CKD patients describes specific methods of exercise therapy for patients with end-stage kidney disease both during dialysis and on non-dialysis days [53]. The American College of Sports Medicine has released guidelines for exercise testing and prescription [54], and specific methods and cautions about exercise therapy for dialysis patients are presented in the latest edition. However, no guideline has evaluated the usefulness of exercise therapy. Therefore, we evaluated the effectiveness of exercise therapy in dialysis patients.

\section{CQ4 Is exercise therapy useful in dialysis patients?}

[Recommendation]

Exercise therapy is recommended for hemodialysis patients, because it has been suggested to improve exercise tolerance, walking ability, and physical QOL [1B]. The effectiveness of exercise therapy for patients on peritoneal dialysis remains to be discussed in the future due to the limitation of evidence.

[Comments]

The survival, exercise tolerance, QOL, physical ability (walking ability), physical function (muscle strength), muscle mass, albumin, ADL, dialysis dose $(\mathrm{Kt} / \mathrm{V})$, and $\mathrm{C}$-reactive protein (CRP) were selected as outcomes.

For systematic review (SR), PubMed was searched for the relevant literature using the search formulas shown 
elsewhere. Initially, 3391 articles were retrieved. Then, through primary screening according to the title and abstract and secondary screening according to the text, 41 RCTs are finally reviewed.

The meta-analysis of these RCTs concerning the effects of exercise therapy during hemodialysis on various outcomes demonstrated that significantly better results were obtained in the exercise therapy group compared to the control group in exercise tolerance [mean difference (MD) in $\mathrm{VO}_{2}: 5.25 \mathrm{~L} / \mathrm{min} / \mathrm{kg}, 95 \%$ confidence interval (CI): 4.30-6.20 L/min $/ \mathrm{kg}$ ] (Fig. 4) [55-66], QOL (MD of physical component summary: 7.39 , 95\% CI 2.26-12.51; MD of mental component summary: $9.46,95 \%$ CI $0.26-$ 18.65) (Fig. 5) [43, 64, 67-70], physical ability (MD of 6-min walking distance: $30.2 \mathrm{~m}, 95 \%$ CI $24.22-36.07 \mathrm{~m}$ ) (Fig. 6) [43, 69, 71-76], and Kt/V (MD 0.07, 95\% CI 0.010.14) (Fig. 7) [43, 66, 67, 71, 77-79]. However, no statistically significant difference was noted in muscle strength $[69,70,76-80]$, muscle mass $[68,71]$, albumin $[43,58,71$, $75,77,79,81,82]$, or CRP $[43,82,83]$, while they were all improved. In addition, the survival (number of patients deceased during the study) was evaluated by post-hoc analysis, but no significant difference was observed while the risk difference (RD) $(-0.00,95 \% \mathrm{CI}-0.02-0.01)$ and point estimate were better in the exercise therapy group (Fig. 8) [29, 43, 55-94].

Concerning the strength of evidence and recommendation grade, the panel conference agreed to rate the strength of evidence as moderate (B) and to strongly recommend exercise therapy to be performed (1B) in consideration of the presence of multiple RCTs, consistency of the effects, and magnitude of the effects.

A previous meta-analysis of exercise therapy [95], demonstrated that greater improvements were observed in exercise tolerance $\left(\mathrm{VO}_{2}\right)$ in clinical studies with an intervention period of $\geq 6$ months than in those with an intervention period of $<6$ months. Moreover, the same meta-analysis showed that the improvement in exercise tolerance was greater in clinical studies using both aerobic exercise therapy and resistance training in combination than aerobic exercise therapy alone. Also, there was a report that the improvement in exercise tolerance was greater by exercise therapy under supervision on non-dialysis days compared with that during dialysis despite a larger number of dropouts [96]. In conducting exercise therapy, the relationship between such specific methods and effectiveness of exercise therapy must be considered.

In the studies reviewed for the preparation of this guideline, none evaluated peritoneal dialysis patients alone, and only two included peritoneal dialysis patients in the subjects $[58,74]$. In most other studies, exercise therapy was performed during dialysis in hemodialysis patients. For the future, it is necessary to validate the optimal method of exercise therapy for peritoneal dialysis patients and its effectiveness. At any rate, the ultimate objective of dialysis therapy is social rehabilitation, and renal rehabilitation per se shares the goal. It is very

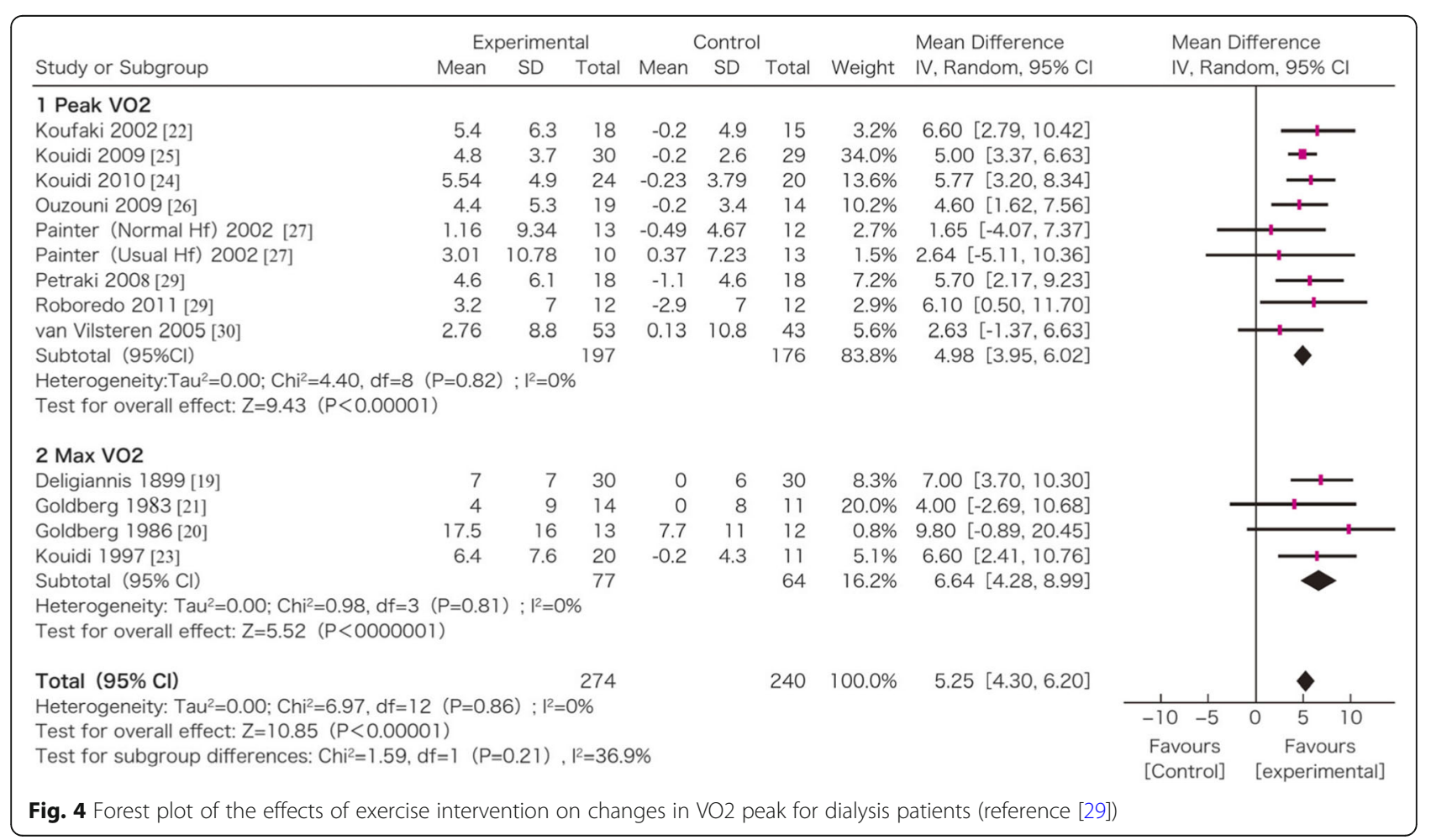




\begin{tabular}{|c|c|c|c|c|c|c|c|c|c|c|}
\hline \multirow[b]{2}{*}{ Study or Subgroup } & \multicolumn{3}{|c|}{ Experimental } & \multicolumn{3}{|c|}{ Control } & \multirow[b]{2}{*}{ Weight } & \multirow{2}{*}{$\begin{array}{l}\text { Mean Difference } \\
\text { IV, Random, } 95 \% \mathrm{Cl}\end{array}$} & \multirow{2}{*}{\multicolumn{2}{|c|}{$\begin{array}{l}\text { Mean Difference } \\
\text { IV, Random, } 95 \% \mathrm{Cl}\end{array}$}} \\
\hline & Mean & SD & Total & Mean & $S D$ & Total & & & & \\
\hline Dobsak 2012 [31] & 5.2 & 4.4 & 11 & -0.8 & 6.8 & 10 & $23.4 \%$ & $6.00[1.05,10.95]$ & & + \\
\hline Giannaki 2013 [32] & 11.5 & 18.4 & 15 & 6.1 & 5.7 & 7 & $13.7 \%$ & $5.40[-4.82,15.82]$ & & - \\
\hline Hristea 2016 [7] & 24.18 & 13.32 & 10 & 95.75 & 21.37 & 11 & $8.3 \%$ & $29.93[14.84,45.02]$ & & \\
\hline Koh 2010 [33] & -8 & 20 & 15 & 0 & 25 & 15 & $7.5 \%$ & $-6.00[1.62,7.56]$ & & 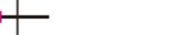 \\
\hline Ouzouni 2009 [26] & -4 & 5.5 & 19 & -0.1 & 5.8 & 14 & $25.5 \%$ & $-1.10[0.18,80.2]$ & & + \\
\hline Song 2012 [34] & 7.9 & 9.9 & 20 & -2.1 & 9.1 & 20 & $21.5 \%$ & $10.00[4.1,15.89]$ & & 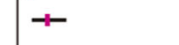 \\
\hline 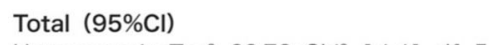 & & & 90 & & & 77 & $100.0 \%$ & $7.39[2.26,12.512]$ & & $\diamond$ \\
\hline \multicolumn{9}{|c|}{ Heterogeneity: $\mathrm{Tau}^{2}=22.78 ; \mathrm{Chi}^{2}=14.41, \mathrm{df}=5 \quad(\mathrm{P}=0.01) ; \mathrm{l}^{2}=65 \%$} & $\frac{1}{-50-25}$ & $\frac{1}{25} 50$ \\
\hline & & & & & & & & & $\begin{array}{l}\text { Favours } \\
\text { [Control] }\end{array}$ & $\begin{array}{c}\text { Favours } \\
\text { [experimental] }\end{array}$ \\
\hline \multicolumn{11}{|l|}{ SF-36 Mental Component Summary } \\
\hline & \multicolumn{3}{|c|}{ Experimental } & \multicolumn{3}{|c|}{ Control } & & Mean Difference & \multirow{2}{*}{\multicolumn{2}{|c|}{$\begin{array}{l}\text { Mean Difference } \\
\text { IV, Random, } 95 \% \mathrm{Cl}\end{array}$}} \\
\hline Study or Subgroup & Mean & SD & Total & Mean & SD & Total & Weight & IV, Random, 95\% Cl & & \\
\hline Dobsak 2012 [31] & 4.7 & 26.7 & 11 & 1 & 5.6 & 10 & $19.9 \%$ & $3.70[-1.06,8.46]$ & & $\leftarrow$ \\
\hline Giannaki 2013 [32] & 9.3 & 10.51 & 15 & 3.1 & 9.9 & 7 & $13.2 \%$ & $6.20[-9.14,21.54]$ & & \\
\hline Hristea 2016 [7] & 30.89 & 20 & 10 & -8.87 & 15.11 & 11 & $15.7 \%$ & $39.76[28.19,51.33]$ & & $\longrightarrow$ \\
\hline Koh 2010 [33] & -2 & 10 & 15 & -2 & 26 & 15 & $12.7 \%$ & $0.00[-16.20,16.20]$ & & \\
\hline Ouzouni 2009 [26] & 0 & 11.6 & 19 & -0.2 & 6.8 & 14 & $19.4 \%$ & $0.20[-5.54,5.94]$ & & - \\
\hline Song 2012 [34] & 6.5 & & 20 & -1.9 & 8.9 & 20 & $\begin{array}{r}19.0 \% \\
100.0 \%\end{array}$ & $8.40[1.99,14.81]$ & & $\rightarrow$ \\
\hline \multirow{3}{*}{\multicolumn{5}{|c|}{$\begin{array}{l}\text { Total }(95 \% \mathrm{Cl}) \\
\text { Heterogeneity: Tau }{ }^{2}=104.85 ; \mathrm{Chi}^{2}=38.59, \mathrm{df}=6 \quad(P<0.00001) ; l^{2}=87 \% \\
\text { Test for overall effect: } Z=2.02 \quad(P=0.04)\end{array}$}} & & 77 & & $9.46[0.26,18.65]$ & & \\
\hline & & & & & & & & & $\frac{1}{-50-25}$ & $25 \quad 50$ \\
\hline & & & & & & & & & $\begin{array}{l}\text { Favours } \\
\text { [Control] }\end{array}$ & $\begin{array}{c}\text { Favours } \\
\text { [experimental] }\end{array}$ \\
\hline
\end{tabular}

significant that the physical ability and QOL were improved by exercise, which is a major component of renal rehabilitation. In this respect, renal rehabilitation plays a major role in achieving the goal of dialysis therapy.

\section{Renal rehabilitation for renal transplant recipients Introduction}

1. Objectives and expected effects

Renal transplantation is a renal replacement therapy along with dialysis therapy for end-stage kidney disease, and, currently, about 15,000 renal transplant recipients with functioning kidney grafts are estimated to be present in Japan [97].

Since renal transplant recipients have less time restrictions than dialysis patients and suffer less from uremia, renal transplantation is considered the optimal treatment for social rehabilitation. Especially, preemptive kidney transplantation (PEKT) without long-term dialysis is recommended as advantageous not only for the prevention of sarcopenia/frailty but also for improving the vital prognosis [98] and QOL [99]. From these viewpoints, also, renal transplantation may be the utmost means for renal rehabilitation.

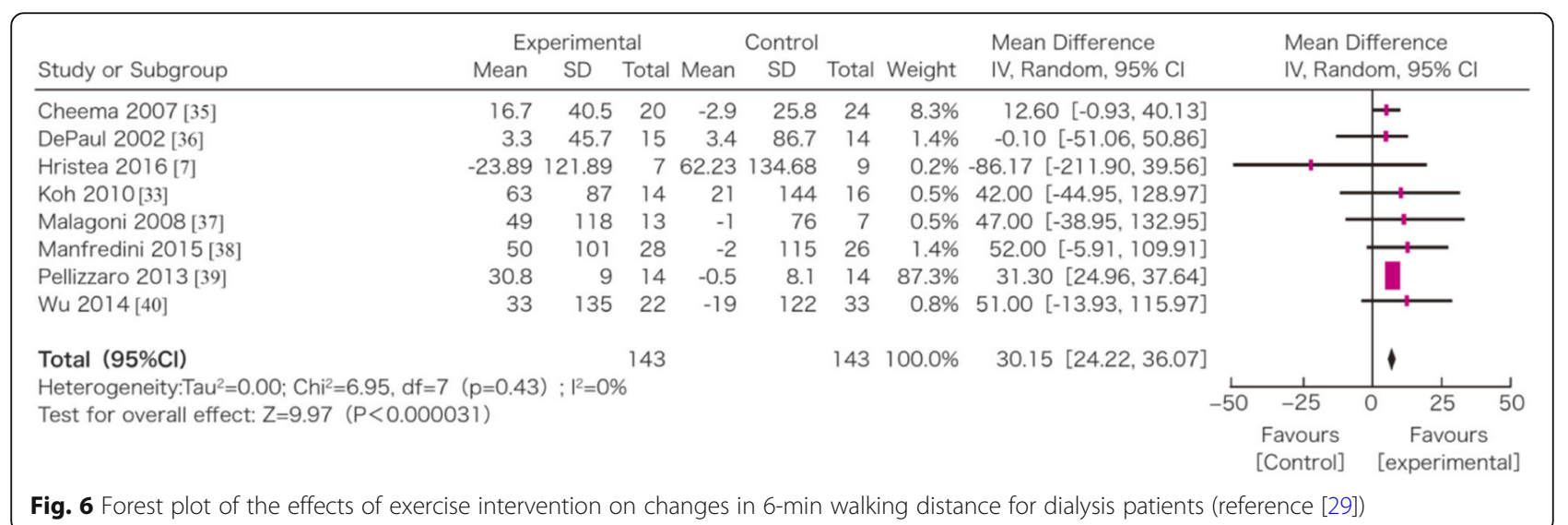




\begin{tabular}{|c|c|c|c|c|c|c|c|c|c|c|}
\hline \multirow{2}{*}{ Study or Subgroup } & \multicolumn{3}{|c|}{ Experimental } & \multicolumn{3}{|c|}{ Control } & \multirow[b]{2}{*}{ Weight } & Mean Difference & \multirow{2}{*}{\multicolumn{2}{|c|}{$\begin{array}{l}\text { Mean Difference } \\
\text { IV, Random, } 95 \% \mathrm{Cl}\end{array}$}} \\
\hline & Mean & SD & Total & Mean & SD & Total & & IV, Random, 95\% Cl & & \\
\hline Cheema 2007 [35] & 0.1 & 0.5 & 20 & 0.1 & 0.4 & 24 & $6.3 \%$ & $0.00[-0.27,0.274]$ & - & - \\
\hline Dobsak 2012 [31] & 0.21 & 0.3 & 11 & -0.08 & 0.31 & 10 & $6.8 \%$ & $0.29[0.03,0.55]$ & & \\
\hline Frey 1999 [41] & 0.1 & 0.3 & 5 & 0 & 0.1 & 6 & $6.2 \%$ & $0.10[-0.17,0.37]$ & & \\
\hline Hristea 2016 [7] & -0.05 & 0.52 & 7 & 0 & 0.4 & 9 & $2.2 \%$ & $-0.05[-0.52,0.42]$ & & \\
\hline Parsons 2004 [42] & 0 & 0.3 & 6 & -0.08 & 0.23 & 7 & $5.4 \%$ & $0.01[-0.21,0.37]$ & $=$ & - \\
\hline Reboredo 2010 [43] & 0.4 & 0.8 & 11 & 0.2 & 0.7 & 11 & $1.2 \%$ & $0.20[-0.43,0.83]$ & & \\
\hline van Vilsteren 2005 [30] & 0.06 & 0.2 & 53 & 0 & 0.2 & 43 & $72.0 \%$ & $0.08[-0.02,0.14]$ & & 7 \\
\hline Total $(95 \% \mathrm{Cl})$ & & & 113 & & & 110 & $100.0 \%$ & $0.07[-0.01,0.14]$ & & $\boldsymbol{\vartheta}$ \\
\hline \multirow{2}{*}{$\begin{array}{l}\text { Heterogeneity:Tau }{ }^{2}=0.00 ; \mathrm{Chi}^{2}=3.49, \mathrm{df}=6 \\
\text { Test for overall effect: } Z=2.15 \quad(P=0.003)\end{array}$} & $(P=0.75)$ & $; l^{2}=0$ & & & & & & -5 & $\frac{1}{-25}$ & $\frac{1}{25} 50$ \\
\hline & & & & & & & & & $\begin{array}{l}\text { Favours } \\
\text { [Control] }\end{array}$ & $\begin{array}{c}\text { Favours } \\
\text { [experimental] }\end{array}$ \\
\hline
\end{tabular}

Concerns important for renal transplant recipients include whether the grafted kidney functions for a long time, whether there is the risk of cardiovascular disease or cancer, and whether transplantation results in QOL and exercise tolerance comparable to those of non-CKD patients.

In Japan, about 1600 cases of renal transplantation are carried out annually, and most of them (1400 cases) are living donor renal transplants, with the remaining (less than 200) being deceased donor renal transplants from brain-dead or non-heart-beating individuals [97]. Many of the renal transplant recipients are younger patients with end-stage kidney disease with fewer complications, but renal transplants in aged patients have increased recently due to improvements in renal transplant therapy. Moreover, the mean survival time of kidney grafts has been prolonged due to the development of immunosuppressants, and recipients themselves are also aging. In such circumstances, renal transplant recipients aged 60 years or above are increasing, and problems such as

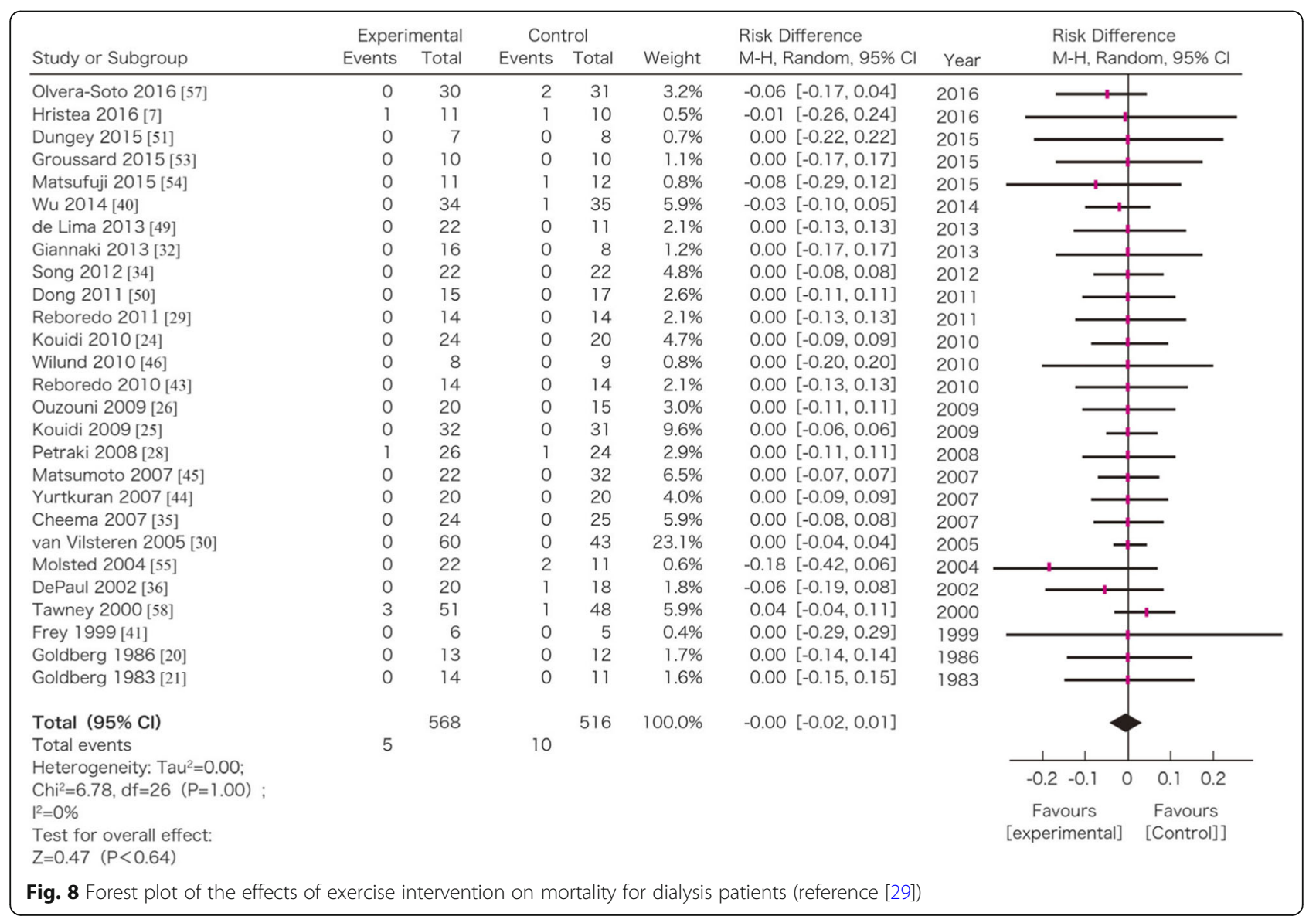


frailty, sarcopenia, and low physical activity after renal transplantation have emerged.

Renal rehabilitation in renal transplant recipients was evaluated by assuming that its objectives and expected effects are maintenance of exercise tolerance and improvement of the QOL via the prevention of frailty/sarcopenia after renal transplantation and the prevention of cardiovascular disease as well as social rehabilitation via the long-term preservation of the graft function and prevention of lifestyle-related disease.

2. Lifestyle modification, dietary counseling, and medications

Renal transplant recipients are orally administered 2-3 immunosuppressants including corticosteroid as long as the kidney graft is functioning. A characteristic of renal transplant recipients is that they become more prone to lifestyle-related diseases such as hypertension, diabetes, and hyperlipidemia due to adverse effects of these immunosuppressants. In addition, they are known to become likely to develop posttransplant metabolic syndrome as they gain weight due to relief from uremia and mitigation of dietary restrictions after renal transplantation [100]. Since posttransplant metabolic syndrome is a risk factor for chronic renal graft dysfunction and cardiovascular disease [101], it is considered best to improve the lifestyle by dietary and exercise therapies.

According to the Clinical Guideline for Medical and Pediatric Complications after Kidney Transplantation 2011 (edited by Japanese Society for Clinical Renal Transplantation, Nihon-Igakukan) [102], it is important first to avoid excessive body weight gain/obesity among points of attention in lifestyle. Specifically, the body weight gain should be controlled within about $5 \%$ of the body weight before transplantation, targeting a body mass index (BMI) of $\leq 25 \mathrm{~kg} / \mathrm{m}^{2}$. Of course, it is also important not to forget taking immunosuppressants and to continue cessation of smoking after transplantation.

As for dietary therapy, there is no strict control of protein, potassium, or phosphorus intake in many patients retaining the renal graft function, and dietary restrictions are relatively mild compared with those of dialysis patients. However, as the renal function of many transplant recipients falls in the range of CKD (eGFR: about $40-50 \mathrm{~mL} / \mathrm{min} / 1.73 \mathrm{~m}^{2}$ ), a well-balanced diet and some restriction of salt intake must be maintained.

On the other hand, in older recipients who are already frail or at a high risk of frailty, since renal failure and corticosteroid can be risk factors for muscle atrophy/ weakness, obesity is often concurrent with sarcopenia. Furthermore, in older people, it is necessary to note that a sufficient energy intake is often difficult to maintain if strict restriction of protein and salt intake similar to that for CKD is imposed and that it may induce exacerbation of sarcopenia and frailty. It is important to evaluate appropriate dietary therapy while assessing the current physical abilities of each recipient. In addition, frailty/ sarcopenia cannot be cured by dietary intake alone. Its combination with exercise therapy is important to allow the ingested nutrients to be catabolized and become a source of energy and muscle. This will be explained in the next section.

\section{Positions of exercise therapy}

Renal transplant recipients often show higher physical activities than patients who have received other renal replacement therapies, and many of them voluntarily take up exercise therapy. Since they have less restriction of time than dialysis patients, they are in a situation more favorable for exercise therapy. However, many of them must continue oral administration of corticosteroid, and they still have the problem of increased risk of osteoporosis and fracture [103].

Because of the recent aging of renal transplant recipients, many questions including the results of renal transplantation in low activity/frail patients with renal failure and whether exercise therapy after renal transplantation is beneficial to them have remained unanswered. Exercise therapy for renal transplant recipients was not described in detail in the Clinical Guideline for Medical and Pediatric Complications after Kidney Transplantation, 2011 [102] or KDIGO Clinical Practice Guideline for the Care of Kidney Transplant Recipient 2009 [104]. In addition, while the exercise protocol for renal transplant recipients is considered to be similar to that for CKD patients, questions such as whether aerobic exercise, resistance training, or their combination is recommendable have not been elucidated.

To solve these problems with exercise therapy after renal transplantation, the present guideline evaluated two themes: "Does frailty/low physical activity affect the prognosis of renal transplant recipients?" and "Can exercise therapy be recommended for renal transplant recipients?"

CQ5 Does frailty/low physical activity affects the prognosis of renal transplant recipients?

[Recommendation]

There is very weak evidence that frailty/low physical activity affects the prognosis of renal transplant recipients. [No recommendation grade]

[Comments]

A recommendation was prepared by the following procedure about the CQ, "Does frailty/low physical activity affect the prognosis of renal transplant recipients?"

To draft the recommendation, exhaustive literature search was carried out in PubMed and Japana Centra Revuo Medicina using the search formulas described 
below on June 21, 2017. By this search, 625 papers were retrieved from PubMed, and 56 papers from Japana Centra Revuo Medicina, and primary screening was performed, resulting in exclusion of 660 papers. Secondary screening was made concerning the remaining 21 papers, and, after exclusion of 13 papers, eight papers were extracted for the preparation of recommendation.

For drafting the recommendation, four factors were evaluated as harmful outcomes: vital prognosis (mortality rate), hospitalization (readmission), duration of hospital stays, and QOL.

The vital prognosis (mortality rate) was evaluated using the papers by Zelle et al. 2011 [105], Rosas et al. 2012 [106], McAdams-DeMarco et al. 2015 [107], and McAdams-DeMarco et al. 2017 [108]. The mortality rate in the frail/low physical activity group was $24.4 \%$ (5.6\% in the control group) [105], 36.3\% (16.3\% in the control group) [106], 22.5\% (8.5\% in the control group) [107], and was higher than in the control group in all reports. The effect of frailty/low physical activity on mortality in the non-frail group in terms of HR compared with the frail group was 0.52 [0.31-0.87] [107], and that in terms of the risk ratio (RR) in the inactive group compared with the active group was 2.17 [1.01-4.65] [107]. As a result of qualitative systematic review, the vital prognosis was generally poorer in frail/low physical activity renal transplant recipients, but the results could not be integrated because of the difference in statistical index of effectiveness among the papers. These results suggest the possibility that frailty/low physical activity adversely affects the vital prognosis of renal transplant recipients.

Hospitalization (readmission) was evaluated using the papers by McAdams-DeMarco, 2013 and Lorenz et al., $2017[109,110]$. The readmission rate in the frail/low physical activity group was $45.8 \%$ (28\% in the control group) and $40 \%$ (10.5\% in the control group), and was higher in the frail/low physical activity group in both reports $[109,110]$. The effect of frailty/low physical activity on readmission in terms of adjusted RR was 1.61 [1.18-2.19] and that in terms of OR was 4.68 [1.6313.45]. As a result of qualitative SR, the readmission rate was generally higher in frail/low physical activity renal transplant recipients, but the results could not be integrated because of the difference in statistical index of effectiveness between the papers. These results suggest the possibility that frailty/low physical activity adversely affects the readmission rate of renal transplant recipients.

The duration of hospital stays was evaluated using the papers by McAdams-DeMarco et al., 2016 and Lorenz et al., 2017 [109, 111]. The effect of frailty/low physical activity on readmission in terms of OR was 1.14 [1.05-1.28] and 3.44 [1.23-10.02]. As a result of qualitative SR, the length of stay was generally longer in frail/inactive renal transplant recipients, but the results could not be integrated because of the difference in the statistical index of effectiveness between the papers. These results suggest the possibility that frailty/low physical activity adversely affects the length of stay of renal transplant recipients.

The QOL was evaluated using the papers by Raymond et al. 2016 and Lorenz et al. 2017 [109, 112]. As a result of qualitative SR, the QOL was generally lower in frail/inactive renal transplant recipients, but the results could not be integrated because of the difference in statistical index of the effectiveness between the papers. These results suggest the possibility that frailty/low physical activity adversely affects the QOL of renal transplant recipients.

On the basis of these results of SR, it may be concluded that frailty/low physical activity may adversely affects the vital prognosis, hospitalization, length of stay, and QOL of renal transplant recipients but that the evidence as a whole is weak. Based on these results, a panel including third-party members adopted the recommendation, "There is very weak evidence that frailty/low physical activity at transplantation affects the prognosis of renal transplant recipients." for the CQ, "Does frailty/low physical activity affect the prognosis of renal transplant recipients?" (no recommendation level).

However, the discussion was made on the assumption that patients with indication for renal transplantation are those who are expected to have a reasonable vital prognosis and in a relatively good physical condition that tolerates general anesthesia among patients with end-stage kidney disease. The results of the present SR suggest the possibility that the prognosis is poorer in frail/inactive renal transplant recipients than in those with no frailty/low physical activity, but it has been reported that the prognosis including vital prognosis of renal transplantation is overwhelmingly better than that of dialysis therapy regardless of the presence or absence

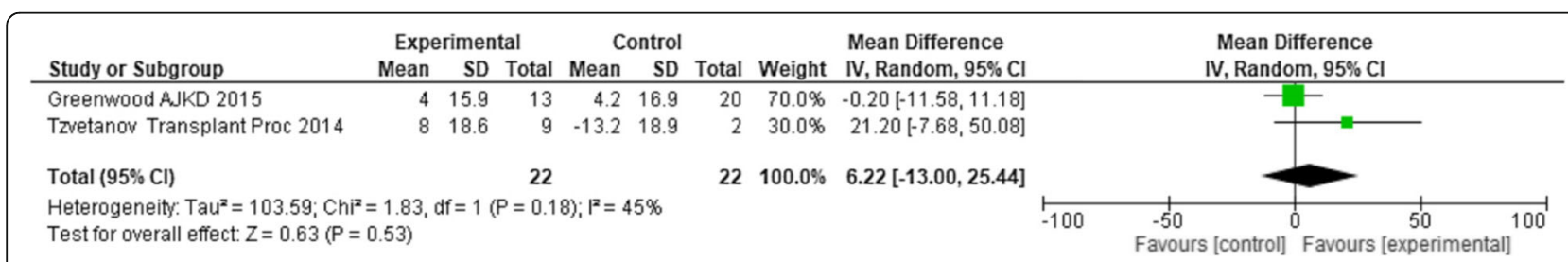

Fig. 9 Forest plot of the effects of exercise intervention on changes in eGFR for transplant patients (reference [115]) 


\begin{tabular}{|c|c|c|c|c|c|c|c|c|c|}
\hline \multirow[b]{2}{*}{ Study or Subgroup } & \multicolumn{3}{|c|}{ Experimental } & \multicolumn{3}{|c|}{ Control } & \multirow[b]{2}{*}{ Weight } & \multirow{2}{*}{$\begin{array}{l}\text { Mean Difference } \\
\text { IV, Random, } 95 \% \mathrm{Cl}\end{array}$} & \multirow{2}{*}{$\begin{array}{c}\text { Mean Difference } \\
\text { IV, Random, } 95 \% \mathrm{Cl}\end{array}$} \\
\hline & Mean & SD & Total & Mean & SD & Total & & & \\
\hline Greenwood AJKD 2015 & 2.7 & 3.9 & 13 & 1 & 3 & 20 & $43.4 \%$ & $1.70[-0.79,4.19]$ & P \\
\hline Kouidi Nephrol Dial Transplant 2013 & 5.4 & 4.8 & 11 & -0.1 & 4.5 & 12 & $25.0 \%$ & $5.50[1.69,9.31]$ & $\Rightarrow$ \\
\hline Painter Transplantation 2002 & 3.8 & 11 & 52 & 3.6 & 9.2 & 43 & $22.7 \%$ & $0.20[-3.86,4.26]$ & + \\
\hline Riess Appl Physiol Nutr Metab 2014 & 3 & 10 & 16 & 0 & 10 & 15 & $8.9 \%$ & $3.00[-4.04,10.04]$ & + \\
\hline Total $(95 \% \mathrm{Cl})$ & & & 92 & & & 90 & $100.0 \%$ & $2.42[0.22,4.63]$ & 6 \\
\hline \multicolumn{6}{|c|}{$\begin{array}{l}\text { Heterogeneity: } \operatorname{Tau}^{2}=1.30 ; \mathrm{Chi}^{2}=3.99, \mathrm{df}=3(\mathrm{P}=0.26) ; \mathrm{I}^{2}=25 \% \\
\text { Test for overall effect. } Z=2.15(P=0.03)\end{array}$} & & & -100 & $\begin{array}{cccc}1 & 1 & 10 \\
-50 & 0 & 50 & 100 \\
\text { Favours [control] } & \text { Favours [experimental] }\end{array}$ \\
\hline
\end{tabular}

of frailty/low physical activity. It should be noted that the results of the present SR do not recommend exclusion of renal transplantation as a treatment for frail/inactive renal failure patients.

CQ6 Can exercise therapy be recommended to renal transplant recipients?

[Recommendation]

Exercise therapy is proposed to be implemented for renal transplant recipients. $[2 \mathrm{C}]$

[Comments]

Recommendation was prepared concerning the $\mathrm{CQ}$, "Can exercise therapy be recommended to renal transplant recipients?" by the following procedure.

To draft the recommendation, exhaustive literature search was performed through PubMed and Japane Centra Revuo Medicina on April 4, 2017, using the search formulas described below. As a result of this search, 1214 papers could be retrieved from PubMed, and 89 papers from the Japana Centra Revuo Medicina, and primary screening was performed, excluding 1270 papers. Secondary screening was performed concerning the remaining 33 papers, and 23 papers were excluded. As a result, ten papers were selected to be reviewed for the preparation of the present recommendation.

To adopt the recommendation, three outcomes, i.e., renal allograft function (eGFR), exercise tolerance $\left(\mathrm{VO}_{2}\right.$ peak), and QOL, were evaluated, and meta-analysis was performed using the reports of six RCTs in which these outcomes were evaluated. In principle, mean values of differences between the pre- and post-intervention values and post-intervention standard deviation (SD) were adopted.

All these studies were RCTs, but as exercise therapy cannot be performed blindly, no measures to unblind the subjects were taken, although random allocation was made. In addition, there were disagreements among the studies in the method or intensity of exercise therapy and time or method of evaluation. Since the exercise therapy consisted primarily of resistance training, the results of resistance training were analyzed as a standard, and papers concerning aerobic exercise therapy alone were negatively rated regarding the indirectness.

The renal allograft function (eGFR) was evaluated using the papers by Tzvetanov et al. 2014, and Greenwood et al. 2015 [113, 114]. The strength of the evidence as a whole was rated as weak $(\mathrm{C})$, because there were marked bias risk, moderate inconsistency, moderate imprecision, and moderate indirectness. As a result of quantitative evaluation of 44 patients in two papers, the integrated value was $6.22[-13.00-25.44] \mathrm{mL} / \mathrm{min} / 1.73 \mathrm{~m}^{2}, p=0.53$, and no reporting bias was observed. These results indicate that significant improvements are not always obtained by exercise therapy in renal transplant recipients in terms of the renal graft function (eGFR) (Fig. 9).

Exercise tolerance $\left(\mathrm{VO}_{2}\right.$ peak) was evaluated using the papers by Painter et al. 2002, Kouidi et al. 2013, Riess et al. 2014, and Greenwood et al. 2015 [114, 116-118]. The evidence as a whole was judged to have marked bias risk, moderate imprecision, and moderate indirectness. On the whole, the strength of evidence was rated as moderate (B). As a result of quantitative evaluation of 182 patients in four papers, the integrated value was $2.42[0.22-4.63] \mathrm{mL} / \mathrm{kg} / \mathrm{min}, p=0.03$, and no reporting bias was observed. These results indicate that exercise therapy significantly improves exercise tolerance $\left(\mathrm{VO}_{2}\right.$ peak) in renal transplant recipients (Fig. 10).

The QOL was evaluated using the papers by Greenwood et al. 2015, Riesse et al. 2014, Painter et al. 2002, and

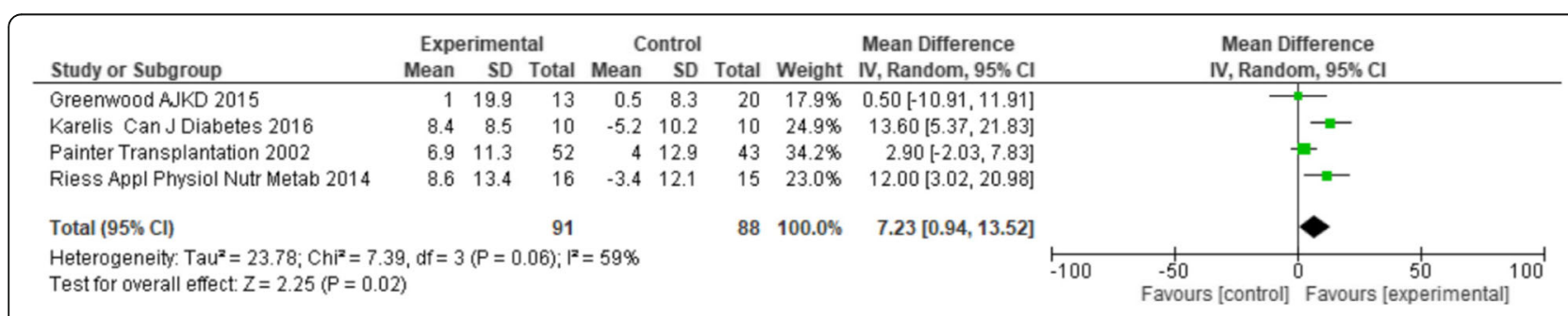

Fig. 11 Forest plot of the effects of exercise intervention on changes in quality of life for transplant patients (reference [115]) 
Karelis et al. 2016 [114, 116, 118, 119]. The outcome index was the SF-36 in some reports and the well-being score in others, but analysis was performed by integrating them. The evidence as a whole was judged to have marked bias risk, moderate imprecision, and moderate indirectness. Negative rating was not made concerning inconsistency, because the effect estimates were in the same direction. On the whole, the strength of evidence was rated as moderate (B). As a result of quantitative evaluation of 179 patients in four reports, the integrated value of the scores was 7.23 [0.94-13.52], $p=0.02$, and no reporting bias was observed. These results indicate that exercise therapy significantly improves the QOL of renal transplant recipients (Fig. 11).

As a result of these SRs, it was concluded that exercise therapy significantly improves exercise tolerance $\left(\mathrm{VO}_{2}\right.$ peak) and QOL of renal transplant recipients but that it does not always significantly improve the renal allograft function (eGFR). Based on these results, the panel including third-party members adopted the recommendation, "Exercise therapy is proposed to be implemented for renal transplant recipients." concerning the $\mathrm{CQ}$, "Can exercise therapy be recommended to renal transplant recipients?" In addition, the present analysis was concerned primarily with intervention by resistance training, but there were also RCTs using aerobic exercise therapy alone or a combination of aerobic exercise therapy and resistance training. Therefore, the recommendation stopped short of addressing the contents, intensity, or period of exercise therapy and referred to exercise therapy in general. At the same time, it should be noted that the evaluation of the risk involved in exercise therapy is insufficient. The precise results of these SRs are shown in our report [115].

\section{Abbreviations \\ ACSM: American College of Sports Medicine; ADL: Activity of daily living; BMI: Body mass index; Cl: Confidence interval; CKD: Chronic kidney disease; CQ: Clinical question; CRP: C-reactive protein; DOPPS: The Dialysis Outcomes and Practice Patterns Study; GFR: Glomerular filtration rate; IgA: Immunoglobulin A; JSRR: Japanese Society of Renal Rehabilitation; KDIGO: Kidney Disease: Improving Global Outcomes; MCNS: Minimal change nephrotic syndrome; MD: Mean difference; METs: Metabolic equivalents; nPCR: Normalized protein catabolic rate; PEKT: Preemptive kidney transplantation; PEW: Protein-energy wasting; QOL: Quality of life; RCT: Randomized controlled trial; RD: Risk difference; RR: Risk ratio; SD: Standard deviation; SF-36: The 36-Item Short Form Health Survey; SR: Systematic review}

\footnotetext{
Acknowledgements

This article is the secondary publication from Japanese version by Japanese Society of Renal Rehabilitation (JSRR) that was published Nankodo publishers Co. Ltd., Tokyo, Japan, with permission. We greatly thank external review teams from the Japanese Society of Nephrology, the Japanese Society for Dialysis Therapy, the Japanese Association of Cardiac Rehabilitation, the Japan Academy of nephrology Nursing, the Japanese Physical Therapy Association, and the Japanese Association of Occupational Therapists for their suggestive advice and cooperation. We also thank all members and staffs of the Japanese Society of Renal Rehabilitation for supports, and thank
}

Mr. Yuji Tatsugami, Sachiko Takahashi, and Naoto Ichijo (Nankodo, Tokyo) for editing the guideline.

Renal Rehabilitation Guideline Preparation Committee, Japanese Society of Renal Rehabilitation

Kunihiro Yamagata; Junichi Hoshino; Hitoshi Sugiyama; Norio Hanafusa; Yugo Shibagaki; Yasuhiro Komatsu; Tsuneo Konta; Naohiko Fujii; Eiichiro Kanda; Tadashi Sofue; Kiyonobu Ishizuka; Masashi Kitagawa; Keiji Kono; Norikazu Hinamoto; Takayuki Miyai; Kiyomi Koike; Susumu Toda; Jumpei Hasegawa; Masayuki Yamanouchi; Ryuichi Yoshimura; Ryota Ishii; Shunsuke Goto; Hiroo Kawarazaki; Kentaro Takase; Fumika Taki; Mimiko Matsumura; Yoshihiko Raita; Satoko Sakurai; Tatsuya Shimizu; Suguru Yamanoto; Takehiko Kawaguchi; Hideyo Oguchi; Makoto Tsujita; Masahiko Yazawa; Akiko Uchida; Yasuhiro Ando; Satoru Kaneko; Atsuhiko Matsunaga; Taku Harada; Osamu Ito; and Masahiro Kohzuki.

\section{Funding}

This work was supported by the Japanese Society of Renal Rehabilitation (JSRR).

\section{Availability of data and materials}

All the meta-analysis data were presented at homepage of the JSRR (https:// jsrr.jimdo.com/).

\section{Authors' contributions}

Work group membership was shown below: Chairman, KY; Steering committee, $\mathrm{KY}, \mathrm{Ol}$, and MK; Secretary general of the committee, JH; Secretary general of the JSRR, TH; Group leaders, JH, HS, NH, YS, and YK; Group subleaders, TK, NF, EK, and TS; systematic review (SR) members of CQ1 and 2, KI, MK, KK, NH, and TM; SR members of CQ3, KK, ST, JH, and MY; SR members of CQ4, RY, RI, SG, HK, KT, FT, MM, YR, SS, TS, and SY; SR members of CQ5 and 6 , TK, HO, MT, and MY: Members of external review board, AU, YA, SK, and AM. All authors have actively participated in this study as well as in writing the manuscript. All authors read and approved the final manuscript.

\section{Ethics approval and consent to participate}

This study does not contain any individual data. All the procedures were performed in accordance with the Unifrom Requirements for Manuscript Submitted to Biomedical Journals, produced by the International Committee of Medical Journal Editors.

\section{Consent for publication}

Not applicable.

\section{Competing interests}

The authors declare that they have no competing interests.

\section{Publisher's Note}

Springer Nature remains neutral with regard to jurisdictional claims in published maps and institutional affiliations.

\section{Author details}

'Department of Nephrology, Faculty of Medicine, University of Tsukuba, 1-1-1, Ten-oudai, Tsukuba, Ibaraki 305-8575, Japan. ${ }^{2}$ Nephrology Center, Toranomon Hospital, Tokyo, Japan. ${ }^{3}$ Department of Human Resource Development of Dialysis Therapy for Kidney Disease, Okayama University Graduate School of Medicine, Dentistry and Pharmaceutical Sciences, Okayama, Japan. ${ }^{4}$ Department of Blood Purification, Tokyo Women's Medical University, Tokyo, Japan. ${ }^{5}$ Department of Nephrology and Hypertension, St Marianna University School of Medicine, Kanagawa, Japan. ${ }^{6}$ Department of Healthcare Quality and Safety, Gunma University Graduate School of Medicine, Gunma, Japan. ${ }^{7}$ Department of Public Health and Hygiene, Yamagata University Graduate School of Medical Science, Yamagata, Japan. ${ }^{8}$ Department of Nephrology, Hyogo Prefectural Nishinomiya Hospital, Hyogo, Japan. ${ }^{9}$ Medical Science, Kawasaki Medical School, Okayama, Japan.

${ }^{10}$ Division of Nephrology and Dialysis, Department of Cardiorenal and Cerebrovascular Medicine, Kagawa University, Kagawa, Japan. ${ }^{11}$ Department of Pediatric Nephrology, Tokyo Women's Medical University, Tokyo, Japan. ${ }^{12}$ Department of Nephrology, Rheumatology, Endocrinology and Metabolism, Okayama University Graduate School of Medicine, Dentistry and Pharmaceutical Sciences, Okayama, Japan. ${ }^{13}$ Division of Nephrology and Kidney Center, Kobe University Graduate School of Medicine, Kobe, Japan. 
${ }^{14}$ Department of Pediatrics, Okayama University Hospital, Okayama, Japan ${ }^{15}$ Department of Kidney Disease Center, Nagoya Daini Red Cross Hospital, Nagoya, Japan. ${ }^{16}$ Department of Nephrology, Uji Takeda Hospital, Kyoto, Japan. ${ }^{17}$ Department of Nephrology, Ohkubo Hospital, Tokyo, Japan. ${ }^{18}$ Nephrology Center, Toranomon Hospital Kajigaya, Kanagawa, Japan. ${ }^{19}$ Division of Nephrology, Shimane University Hospital, Shimane, Japan. ${ }^{20}$ Department of Nephrology, Inagi Municipal Hospital, Tokyo, Japan. ${ }^{21}$ Division of Nephrology, St. Luke's International Hospital, Tokyo, Japan. ${ }^{22}$ Department of Nephrology, Tokyo Teishin Hospital, Tokyo, Japan. ${ }^{23}$ Division of Nephrology, Okinawa Chubu Hospital, Okinawa, Japan. ${ }^{24}$ Division of Nephrology and Endocrinology, The University of Tokyo Graduate School of Medicine, Tokyo, Japan. ${ }^{25}$ Division of Clinical Nephrology and Rheumatology, Niigata University Graduate School of Medical and Dental Sciences, Niigata, Japan. ${ }^{26}$ Department of Nephrology, Chiba East Hospital, Chiba, Japan. ${ }^{27}$ Department of Nephrology, Toho University Faculty of Medicine, Tokyo, Japan. ${ }^{28}$ Department of Nursing Management, Seirei Social Welfare Community Seirei Yokohama Hospital, Kanagawa, Japan. ${ }^{29}$ Division of Nephrology, Preventive Medicine Center, International University of Health and Welfare Hospital, Tochigi, Japan. ${ }^{30}$ Japan Association of Kidney Disease Patients, Tokyo, Japan. ${ }^{31}$ Department of Rehabilitation Sciences, Kitasato University Graduate School of Medical Sciences, Kanagawa, Japan.

${ }^{32}$ Department of Internal Medicine \& Rehabilitation Science, Tohoku University Graduate School of Medicine, Sendai, Japan. ${ }^{33}$ Division of General Medicine and Rehabilitation, Tohoku Medical Pharmaceutical University Faculty of Medicine, Sendai, Japan.

Received: 22 December 2018 Accepted: 26 March 2019

Published online: 13 June 2019

\section{References}

1. Fuiano G, Mancuso D, Cianfrone P, Comi N, Mazza G, Marino F, et al. Can young adult patients with proteinuric IgA nephropathy perform physical exercise? Am J Kidney Dis. 2004;44(2):257-63.

2. Yoshida S. Ventilatory threshold in patients with chronic glomerulonephritis. Nihon Jinzo Gakkai shi. 1993;35(6):695-703.

3. Berg U, Bohlin AB, Freyschuss U, Johansson BL, Lefvert AK. Renal function and albumin excretion during exercise in children during remission of the minimal change nephrotic syndrome. Acta Paediatr Scand. 1988;77(2):287-93.

4. Cupisti A, Chisari C, Morelli E, Meola M, Giannini E, Rossi B, et al. Abnormal increase of creatine kinase plasma levels following muscle exercise in nephrotic patients. Nephron. 1998:80(2):204-7.

5. Heiwe S, Tollback A, Clyne N. Twelve weeks of exercise training increases muscle function and walking capacity in elderly predialysis patients and healthy subjects. Nephron. 2001;88(1):48-56.

6. Clyne N, Ekholm J, Jogestrand T, Lins LE, Pehrsson SK. Effects of exercise training in predialytic uremic patients. Nephron. 1991;59(1):84-9.

7. Painter PL, Nelson-Worel JN, Hill MM, Thornbery DR, Shelp WR, Harrington AR, et al. Effects of exercise training during hemodialysis. Nephron. 1986; 43(2):87-92

8. Tsubakihara Y, Nishi S, Akiba T, Hirakata H, Iseki K, Kubota M, et al. 2008 Japanese Society for Dialysis Therapy: guidelines for renal anemia in chronic kidney disease. Ther Apher Dial. 2010;14(3):240-75.

9. Ott SM. Therapy for patients with CKD and low bone mineral density. Nat Rev Nephrol. 2013;9(11):681-92.

10. Fahal $H$. Uraemic sarcopenia: aetiology and implications. Nephrol Dial Transplant. 2014;29(9):1655-65.

11. Tamaki M, Miyashita K, Wakino S, Mitsuishi M, Hayashi K, Itoh H. Chronic kidney disease reduces muscle mitochondria and exercise endurance and its exacerbation by dietary protein through inactivation of pyruvate dehydrogenase. Kidney Int. 2014;85(6):1330-9.

12. Tamaki M, Hagiwara A, Miyashita K, Wakino S, Inoue H, Fujii K, et al. Improvement of physical decline through combined effects of muscle enhancement and mitochondrial activation by a gastric hormone ghrelin in male 5/6Nx CKD model mice. Endocrinology. 2015;156(10):3638-48.

13. Heiwe $\mathrm{S}$, Clyne N, Tollback A, Borg K. Effects of regular resistance training on muscle histopathology and morphometry in elderly patients with chronic kidney disease. Am J Phys Med Rehabil. 2005;84(11):865-74.

14. Inker LA, Astor BC, Fox CH, Isakova T, Lash JP, Peralta CA, et al. KDOQI US commentary on the $2012 \mathrm{KDIGO}$ clinical practice guideline for the evaluation and management of CKD. Am J Kidney Dis. 2014;63(5):713-35.
15. Garber CE, Blissmer B, Deschenes MR, Franklin BA, Lamonte MJ, Lee IM, et al. American College of Sports Medicine position stand. Quantity and quality of exercise for developing and maintaining cardiorespiratory, musculoskeletal, and neuromotor fitness in apparently healthy adults: guidance for prescribing exercise. Med Sci Sports Exerc. 2011;43(7):1334-59.

16. Howden EJ, Coombes JS, Strand H, Douglas B, Campbell KL, Isbel NM. Exercise training in CKD: efficacy, adherence, and safety. Am J Kidney Dis. 2015;65(4):583-91.

17. Watson EL, Greening NJ, Viana JL, Aulakh J, Bodicoat DH, Barratt J, et al. Progressive resistance exercise training in CKD: a feasibility study. Am J Kidney Dis. 2015;66(2):249-57.

18. Castaneda C, Gordon PL, Uhlin KL, Levey AS, Kehayias JJ, Dwyer JT, et al. Resistance training to counteract the catabolism of a low-protein diet in patients with chronic renal insufficiency. A randomized, controlled trial. Ann Intern Med. 2001;135(11):965-76.

19. Rossi AP, Burris DD, Lucas FL, Crocker GA, Wasserman JC. Effects of a renal rehabilitation exercise program in patients with CKD: a randomized controlled trial. Clin J Am Soc Nephrol. 2014;9(12):2052-8.

20. Gong Q, Gregg EW, Wang J, An Y, Zhang P, Yang W, et al. Long-term effects of a randomised trial of a 6-year lifestyle intervention in impaired glucose tolerance on diabetes-related microvascular complications: the China Da Qing diabetes prevention outcome study. Diabetologia. 2011; 54(2):300-7.

21. Look_AHEAD_Research_Group. Effect of a long-term behavioural weight loss intervention on nephropathy in overweight or obese adults with type 2 diabetes: a secondary analysis of the look AHEAD randomised clinical trial. Lancet Diabetes Endocrinol. 2014;2(10):801-9.

22. Eidemak I, Haaber AB, Feldt-Rasmussen B, Kanstrup IL, Strandgaard S. Exercise training and the progression of chronic renal failure. Nephron. 1997:75(1):36-40.

23. Aoike DT, Baria F, Kamimura MA, Ammirati A, de Mello MT, Cuppari L. Impact of home-based aerobic exercise on the physical capacity of overweight patients with chronic kidney disease. Int Urol Nephrol. 2015 47(2):359-67.

24. Greenwood SA, Koufaki P, Mercer TH, MacLaughlin HL, Rush R, Lindup H, et al. Effect of exercise training on estimated GFR, vascular health, and cardiorespiratory fitness in patients with CKD: a pilot randomized controlled trial. Am J Kidney Dis. 2015;65(3):425-34.

25. Straznicky NE, Grima MT, Lambert EA, Eikelis N, Dawood T, Lambert GW, et al. Exercise augments weight loss induced improvement in renal function in obese metabolic syndrome individuals. J Hypertens. 2011;29(3):553-64.

26. Leehey DJ, Moinuddin I, Bast JP, Qureshi S, Jelinek CS, Cooper C, et al. Aerobic exercise in obese diabetic patients with chronic kidney disease: a randomized and controlled pilot study. Cardiovasc Diabetol. 2009;8:62

27. Baria F, Kamimura MA, Aoike DT, Ammirati A, Rocha ML, de Mello MT, et al. Randomized controlled trial to evaluate the impact of aerobic exercise on visceral fat in overweight chronic kidney disease patients. Nephrol Dial Transplant. 2014;29(4):857-64

28. Leehey DJ, Collins E, Kramer HJ, Cooper C, Butler J, McBurney C, et al. Structured exercise in obese diabetic patients with chronic kidney disease: a randomized controlled trial. Am J Nephrol. 2016:44(1):54-62

29. Japanese_Society_of_Renal_Rehabilitation. Guideline for renal rehabilitation 2018. Tokyo: Nankodo; 2018

30. Mustata S, Groeneveld S, Davidson W, Ford G, Kiland K, Manns B. Effects of exercise training on physical impairment, arterial stiffness and health-related quality of life in patients with chronic kidney disease: a pilot study. Int Urol Nephrol. 2011;43(4):1133-41.

31. Headley S, Germain M, Milch C, Pescatello L, Coughlin MA, Nindl BC, et al. Exercise training improves HR responses and $\mathrm{V}$ O2peak in predialysis kidney patients. Med Sci Sports Exerc. 2012;44(12):2392-9.

32. Van Craenenbroeck AH, Van Craenenbroeck EM, Van Ackeren $K$, Vrints CJ, Conraads VM, Verpooten GA, et al. Effect of moderate aerobic exercise training on endothelial function and arterial stiffness in CKD stages 3-4: a randomized controlled trial. Am J Kidney Dis. 2015:66(2): 285-96.

33. Headley S, Germain M, Wood R, Joubert J, Milch C, Evans E, et al. Short-term aerobic exercise and vascular function in CKD stage 3: a randomized controlled trial. Am J Kidney Dis. 2014:64(2):222-9.

34. Howden EJ, Leano R, Petchey W, Coombes JS, Isbel NM, Marwick TH. Effects of exercise and lifestyle intervention on cardiovascular function in CKD. Clin J Am Soc Nephrol. 2013;8(9):1494-501. 
35. Toyama K, Sugiyama S, Oka H, Sumida H, Ogawa H. Exercise therapy correlates with improving renal function through modifying lipid metabolism in patients with cardiovascular disease and chronic kidney disease. J Cardiol. 2010;56(2):142-6.

36. Kosmadakis GC, John SG, Clapp EL, Viana JL, Smith AC, Bishop NC, et al. Benefits of regular walking exercise in advanced pre-dialysis chronic kidney disease. Nephrol Dial Transplant. 2012;27(3):997-1004.

37. Masakane I, Taniguchi M, Nakai S, Tsuchida K, Goto S, Wada A, et al. Annual Dialysis data report 2015, JSDT renal data registry. Ren Replace Ther. 2018; 4(1):19.

38. Kim JC, Kalantar-Zadeh K, Kopple JD. Frailty and protein-energy wasting in elderly patients with end stage kidney disease. J Am Soc Nephrol. 2013; 24(3):337-51.

39. Johansen KL, Chertow GM, Jin C, Kutner NG. Significance of frailty among dialysis patients. J Am Soc Nephrol. 2007:18(11):2960-7.

40. Eriguchi R, Obi Y, Streja E, Tortorici AR, Rhee CM, Soohoo M, et al. Longitudinal associations among renal urea clearance-corrected normalized protein catabolic rate, serum albumin, and mortality in patients on hemodialysis. Clin J Am Soc Nephrol. 2017;12(7):1109-17.

41. Slomowitz LA, Monteon FJ, Grosvenor M, Laidlaw SA, Kopple JD. Effect of energy intake on nutritional status in maintenance hemodialysis patients. Kidney Int. 1989;35(2):704-11

42. Nakao T, Kanno Y, Nagasawa Y. Dietary recommendations for chronic Dialysis patients [in Japanese]. J Jpn Soc Dial Ther. 2014;47:287-91.

43. Hristea D, Deschamps T, Paris A, Lefrancois G, Collet V, Savoiu C, et al. Combining intra-dialytic exercise and nutritional supplementation in malnourished older haemodialysis patients: Towards better quality of life and autonomy. Nephrology (Carlton, Vic). 2016;21(9):785-90.

44. Unruh M, Benz R, Greene T, Yan G, Beddhu S, DeVita M, et al. Effects of hemodialysis dose and membrane flux on health-related quality of life in the HEMO study. Kidney Int. 2004;66(1):355-66.

45. Chertow GM, Levin NW, Beck GJ, Depner TA, Eggers PW, Gassman JJ, et al. In-center hemodialysis six times per week versus three times per week. $N$ Engl J Med. 2010;363(24):2287-300.

46. Minakuchi J, Tomo T, Masakane I. JSDT "Guidelines for maintenance hemodialysis: hemodialysis prescriptions". J Jpn Soc Dial Ther. 2013;46:587-632

47. Al-Hilali N, Al-Humoud H, Nampoory M, Ninan A, Johny K. Outcome and survival in different peritoneal dialysis modalities. Ther Apher Dial. 2007; 11(2):101-6

48. Johansen KL, Finkelstein FO, Revicki DA, Evans C, Wan S, Gitlin M, et al. Systematic review of the impact of erythropoiesis-stimulating agents on fatigue in dialysis patients. Nephrol Dial Transplant. 2012;27(6):2418-25.

49. Yamamoto H, Nishi S, Tomo T, Masakane I, Saito K, Nangaku M, et al. 2015 Japanese Society for Dialysis Therapy: guidelines for renal Anemia in chronic kidney disease. Ren Replace Ther. 2017;3(1):36

50. Avesani CM, Trolonge S, Deleaval P, Baria F, Mafra D, Faxen-Irving G, et al. Physical activity and energy expenditure in haemodialysis patients: an international survey. Nephrol Dial Transplant. 2012;27(6):2430-4

51. Sterky E, Stegmayr BG. Elderly patients on haemodialysis have $50 \%$ less functional capacity than gender- and age-matched healthy subjects. Scand J Urol Nephrol. 2005;39(5):423-30.

52. Tentori F, Elder SJ, Thumma J, Pisoni RL, Bommer J, Fissell RB, et al. Physical exercise among participants in the Dialysis outcomes and practice patterns study (DOPPS): correlates and associated outcomes. Nephrol Dial Transplant. 2010;25(9):3050-62.

53. Smart NA, Williams AD, Levinger I, Selig S, Howden E, Coombes JS, et al. Exercise \& Sports Science Australia (ESSA) position statement on exercise and chronic kidney disease. J Sci Med Sport. 2013;16(5):406-11.

54. American_College_of_Sports_Medicine. ACSM's Guidelines for Exercise Testing and Prescription. 10th ed. Wolters Kluwer Health; 2016.

55. Deligiannis A, Kouidi E, Tourkantonis A. Effects of physical training on heart rate variability in patients on hemodialysis. Am J Cardiol. 1999;84(2):197-202.

56. Goldberg AP, Geltman EM, Gavin JR 3rd, Carney RM, Hagberg JM, Delmez $\mathrm{J} A$, et al. Exercise training reduces coronary risk and effectively rehabilitates hemodialysis patients. Nephron. 1986;42(4):311-6.

57. Goldberg AP, Geltman EM, Hagberg JM, Gavin JR 3rd, Delmez JA, Carney RM, et al. Therapeutic benefits of exercise training for hemodialysis patients. Kidney Int Suppl. 1983;16:S303-9.

58. Koufaki P, Mercer TH, Naish PF. Effects of exercise training on aerobic and functional capacity of end-stage renal disease patients. Clin Physiol Funct Imaging. 2002;22(2):115-24
59. Kouidi E, lacovides A, lordanidis P, Vassiliou S, Deligiannis A, lerodiakonou C, et al. Exercise renal rehabilitation program: psychosocial effects. Nephron. 1997;77(2):152-8.

60. Kouidi E, Karagiannis V, Grekas D, lakovides A, Kaprinis G, Tourkantonis A, et al. Depression, heart rate variability, and exercise training in dialysis patients. Eur J Cardiovasc Prev Rehabil: official journal of the European Society of Cardiology, Working Groups on Epidemiology \& Prevention and Cardiac Rehabilitation and Exercise Physiology. 2010;17(2):160-7.

61. Kouidi EJ, Grekas DM, Deligiannis AP. Effects of exercise training on noninvasive cardiac measures in patients undergoing long-term hemodialysis: a randomized controlled trial. Am J Kidney Dis. 2009;54(3): 511-21.

62. Petraki M, Kouidi E, Grekas D, Deligiannis A. Effects of exercise training during hemodialysis on cardiac baroreflex sensitivity. Clin Nephrol. 2008; 70(3):210-9.

63. Painter P, Moore G, Carlson L, Paul S, Myll J, Phillips W, et al. Effects of exercise training plus normalization of hematocrit on exercise capacity and health-related quality of life. Am J Kidney Dis. 2002;39(2):257-65.

64. Ouzouni S, Kouidi E, Sioulis A, Grekas D, Deligiannis A. Effects of intradialytic exercise training on health-related quality of life indices in haemodialysis patients. Clin Rehabil. 2009;23(1):53-63.

65. Reboredo MM, Neder JA, Pinheiro BV, Henrique DM, Faria RS, Paula RB. Constant work-rate test to assess the effects of intradialytic aerobic training in mildly impaired patients with end-stage renal disease: a randomized controlled trial. Arch Phys Med Rehabil. 2011;92(12):2018-24.

66. van Vilsteren $\mathrm{MC}$, de Greef $\mathrm{MH}$, Huisman RM. The effects of a low-tomoderate intensity pre-conditioning exercise programme linked with exercise counselling for sedentary haemodialysis patients in the Netherlands: results of a randomized clinical trial. Nephrol Dial Transplant. 2005:20(1):141-6.

67. Dobsak P, Homolka P, Svojanovsky J, Reichertova A, Soucek M, Novakova M, et al. Intra-dialytic electrostimulation of leg extensors may improve exercise tolerance and quality of life in hemodialyzed patients. Artif Organs. 2012; 36(1):71-8.

68. Giannaki CD, Sakkas GK, Karatzaferi C, Hadjigeorgiou GM, Lavdas E, Kyriakides $\mathrm{T}$, et al. Effect of exercise training and dopamine agonists in patients with uremic restless legs syndrome: a six-month randomized, partially double-blind, placebo-controlled comparative study. BMC Nephrol. 2013;14:194.

69. Koh KP, Fassett RG, Sharman JE, Coombes JS, Williams AD. Effect of intradialytic versus home-based aerobic exercise training on physical function and vascular parameters in hemodialysis patients: a randomized pilot study. Am J Kidney Dis. 2010;55(1):88-99.

70. Song WJ, Sohng KY. Effects of progressive resistance training on body composition, physical fitness and quality of life of patients on hemodialysis. J Korean Acad Nurs. 2012;42(7):947-56.

71. Cheema B, Abas H, Smith B, O'Sullivan A, Chan M, Patwardhan A, et al. Progressive exercise for anabolism in kidney disease (PEAK): a randomized, controlled trial of resistance training during hemodialysis. J Am Soc Nephrol. 2007;18(5):1594-601.

72. DePaul V, Moreland J, Eager T, Clase CM. The effectiveness of aerobic and muscle strength training in patients receiving hemodialysis and EPO: a randomized controlled trial. Am J Kidney Dis. 2002;40(6):1219-29.

73. Malagoni AM, Catizone L, Mandini S, Soffritti S, Manfredini R, Boari B, et al. Acute and long-term effects of an exercise program for dialysis patients prescribed in hospital and performed at home. J Nephrol. 2008;21(6):871-8.

74. Manfredini F, Lamberti N, Malagoni AM, Felisatti M, Zuccala A, Torino C, et al. The role of deconditioning in the end-stage renal disease myopathy: physical exercise improves altered resting muscle oxygen consumption. Am Jephrol. 2015:41(4-5):329-36.

75. Pellizzaro CO, Thome FS, Veronese FV. Effect of peripheral and respiratory muscle training on the functional capacity of hemodialysis patients. Ren Fail. 2013;35(2):189-97

76. Wu Y, He Q, Yin X, He Q, Cao S, Ying G. Effect of individualized exercise during maintenance haemodialysis on exercise capacity and health-related quality of life in patients with uraemia. J Int Med Res. 2014;42(3):718-27.

77. Frey S, Mir AR, Lucas M. Visceral protein status and caloric intake in exercising versus nonexercising individuals with end-stage renal disease. J Ren Nutr. 1999;9(2):71-7.

78. Parsons TL, Toffelmire EB, King-VanVlack CE. The effect of an exercise program during hemodialysis on dialysis efficacy, blood pressure and 
quality of life in end-stage renal disease (ESRD) patients. Clin Nephrol. 2004; 61(4):261-74.

79. Reboredo Mde M, Pinheiro Bdo V, Neder JA, Avila MP, Araujo ERML, de Mendonca $A F$, et al. Effects of aerobic training during hemodialysis on heart rate variability and left ventricular function in end-stage renal disease patients. Jornal brasileiro de nefrologia : 'orgao oficial de Sociedades Brasileira e Latino-Americana de Nefrologia. 2010;32(4):367-73.

80. Yurtkuran M, Alp A, Yurtkuran M, Dilek K. A modified yoga-based exercise program in hemodialysis patients: a randomized controlled study. Complement Ther Med. 2007:15(3):164-71.

81. Matsumoto Y, Furuta A, Furuta S, Miyajima M, Sugino T, Nagata K, et al. The impact of pre-dialytic endurance training on nutritional status and quality of life in stable hemodialysis patients (Sawada study). Ren Fail. 2007;29(5):587-93.

82. Wilund KR, Tomayko EJ, Wu PT, Ryong Chung H, Vallurupalli S, Lakshminarayanan $\mathrm{B}$, et al. Intradialytic exercise training reduces oxidative stress and epicardial fat: a pilot study. Nephrol Dial Transplant. 2010;25(8): 2695-701.

83. Afshar R, Emany A, Saremi A, Shavandi N, Sanavi S. Effects of intradialytic aerobic training on sleep quality in hemodialysis patients. Iran J Kidney Dis. 2011;5(2):119-23.

84. Carney RM, McKevitt PM, Goldberg AP, Hagberg J, Delmez JA, Harter HR. Psychological effects of exercise training in hemodialysis patients. Nephron. 1983;33(3):179-81.

85. de Lima MC, Cicotoste Cde L, Cardoso Kda S, Forgiarini LA Jr, Monteiro MB, Dias AS. Effect of exercise performed during hemodialysis: strength versus aerobic. Ren Fail. 2013;35(5):697-704.

86. Dong J, Sundell MB, Pupim LB, Wu P, Shintani A, Ikizler TA. The effect of resistance exercise to augment long-term benefits of intradialytic oral nutritional supplementation in chronic hemodialysis patients. J Ren Nutr. 2011;21(2):149-59.

87. Dungey M, Bishop NC, Young HM, Burton JO, Smith AC. The impact of exercising during Haemodialysis on blood pressure, markers of cardiac injury and systemic inflammation--preliminary results of a pilot study. Kidney Blood Press Res. 2015;40(6):593-604.

88. Fitts SS, Guthrie MR, Blagg CR. Exercise coaching and rehabilitation counseling improve quality of life for predialysis and dialysis patients. Nephron. 1999;82(2):115-21.

89. Groussard C, Rouchon-lsnard M, Coutard C, Romain F, Malarde L, LemoineMorel $S$, et al. Beneficial effects of an intradialytic cycling training program in patients with end-stage kidney disease. Applied physiology, nutrition, and metabolism = Physiologie appliquee, nutrition et metabolisme. 2015; 40(6):550-6.

90. Matsufuji S, Shoji T, Yano Y, Tsujimoto Y, Kishimoto H, Tabata T, et al. Effect of chair stand exercise on activity of daily living: a randomized controlled trial in hemodialysis patients. J Ren Nutr. 2015;25(1):17-24.

91. Molsted S, Eidemak I, Sorensen HT, Kristensen JH. Five months of physical exercise in hemodialysis patients: effects on aerobic capacity, physical function and self-rated health. Nephron Clin Pract. 2004;96(3):c76-81.

92. Mortazavi M, Vahdatpour B, Ghasempour A, Taheri D, Shahidi S, Moeinzadeh $F$, et al. Aerobic exercise improves signs of restless leg syndrome in end stage renal disease patients suffering chronic hemodialysis. Sci World J. 2013;2013:628142.

93. Olvera-Soto MG, Valdez-Ortiz R, Lopez Alvarenga JC, Espinosa-Cuevas ML. Effect of resistance exercises on the indicators of muscle reserves and handgrip strength in adult patients on hemodialysis. J Ren Nutr. 2016;26(1):53-60.

94. Tawney KW, Tawney PJ, Hladik G, Hogan SL, Falk RJ, Weaver C, et al. The life readiness program: a physical rehabilitation program for patients on hemodialysis. Am J Kidney Dis. 2000;36(3):581-91.

95. Sheng K, Zhang P, Chen L, Cheng J, Wu C, Chen J. Intradialytic exercise in hemodialysis patients: a systematic review and meta-analysis. Am J Nephrol. 2014;40(5):478-90.

96. Konstantinidou E, Koukouvou G, Kouidi E, Deligiannis A, Tourkantonis A. Exercise training in patients with end-stage renal disease on hemodialysis: comparison of three rehabilitation programs. J Rehabil Med. 2002;34(1):40-5.

97. Japanese Society for Clinical Renal Transplantation / The Japan Society for T. Annual progress report from the Japanese renal transplant registry: number of renal transplantations in 2016 and follow-up survey. Japanese J Transplantation. 2017:52(2-3):113-33.

98. Goto N, Okada M, Yamamoto T, Tsujita M, Hiramitsu T, Narumi S, et al. Association of Dialysis Duration with outcomes after transplantation in a Japanese cohort. Clin J Am Soc Nephrol. 2016;11(3):497-504.
99. Sebille V, Hardouin JB, Giral M, Bonnaud-Antignac A, Tessier P, Papuchon E, et al. Prospective, multicenter, controlled study of quality of life, psychological adjustment process and medical outcomes of patients receiving a preemptive kidney transplant compared to a similar population of recipients after a dialysis period of less than three years--the PreKit-QoL study protocol. BMC Nephrol. 2016;17:11.

100. Johnson CP, Gallagher-Lepak S, Zhu YR, Porth C, Kelber S, Roza AM, et al. Factors influencing weight gain after renal transplantation. Transplantation. 1993:56(4):822-7.

101. Ducloux D, Kazory A, Simula-Faivre D, Chalopin JM. One-year post-transplant weight gain is a risk factor for graft loss. Am J Transplant Off J Am Soc Transplant Am Soc Transplant Surg. 2005;5(12):2922-8.

102. Japanese_Society for_Clinical_Renal_Transplantation. The Clinical Guideline for Medical and Pediatric Complications after Kidney Transplantation [in Japanese]: NIHON IGAKUKAN; 2011.

103. Nikkel LE, Hollenbeak CS, Fox EJ, Uemura T, Ghahramani N. Risk of fractures after renal transplantation in the United States. Transplantation. 2009:87(12): $1846-51$.

104. KDIGO clinical practice guideline for the care of kidney transplant recipients. American journal of transplantation : official journal of the American Society of Transplantation and the American Society of Transplant Surgeons. 2009;9 Suppl 3:S1-155.

105. Zelle DM, Corpeleijn E, Stolk RP, de Greef MH, Gans RO, van der Heide $\mathrm{JJ}$, et al. Low physical activity and risk of cardiovascular and all-cause mortality in renal transplant recipients. Clin J Am Soc Nephrol. 2011; 6(4):898-905.

106. Rosas SE, Reese PP, Huan Y, Doria C, Cochetti PT, Doyle A. Pretransplant physical activity predicts all-cause mortality in kidney transplant recipients. Am J Nephrol. 2012;35(1):17-23.

107. McAdams-DeMarco MA, Law A, King E, Orandi B, Salter M, Gupta N, et al. Frailty and mortality in kidney transplant recipients. Am J Transplant Off J Am Soc Transplant Am Soc Transplant Surg. 2015;15(1):149-54.

108. McAdams-DeMarco MA, Ying H, Olorundare I, King EA, Haugen C, Buta B, et al. Individual frailty components and mortality in kidney transplant recipients. Transplantation. 2017;101(9):2126-32.

109. Lorenz EC, Cheville AL, Amer H, Kotajarvi BR, Stegall MD, Petterson TM, et al. Relationship between pre-transplant physical function and outcomes after kidney transplant. Clin Transplant. 2017;31(5).

110. McAdams-DeMarco MA, Law A, Salter ML, Chow E, Grams M, Walston J, et al. Frailty and early hospital readmission after kidney transplantation. Am J Transplant Off J Am Soc Transplant Am Soc Transplant Surg. 2013;13(8):2091-5.

111. McAdams-DeMarco MA, King EA, Luo X, Haugen C, DiBrito S, Shaffer A, et al. Frailty, length of stay, and mortality in kidney transplant recipients: a National Registry and prospective cohort study. Ann Surg. 2017;266(6):1084-90.

112. Raymond J, Johnson ST, Diehl-Jones W, Vallance JK. Walking, sedentary time and health-related quality life among kidney transplant recipients: An exploratory study. Transplant Proc. 2016;48(1):59-64.

113. Tzvetanov I, West-Thielke P, D'Amico G, Johnsen M, Ladik A, Hachaj G, et al. A novel and personalized rehabilitation program for obese kidney transplant recipients. Transplant Proc. 2014;46(10):3431-7.

114. Greenwood SA, Koufaki P, Mercer TH, Rush R, O'Connor E, Tuffnell R, et al. Aerobic or resistance training and pulse wave velocity in kidney transplant recipients: a 12-week pilot randomized controlled trial (the exercise in renal transplant [ExeRT] trial). Am J Kidney Dis. 2015;66(4):689-98.

115. Oguchi H, Tsujita M, Yazawa M, Kawaguchi T, Hoshino J, Kohzuki M, et al. The efficacy of exercise training in kidney transplant recipients: a metaanalysis and systematic review. Clin Exp Nephrol. 2019;23(2):275-84.

116. Painter PL, Hector L, Ray K, Lynes L, Dibble S, Paul SM, et al. A randomized trial of exercise training after renal transplantation. Transplantation. 2002;74(1):42-8.

117. Kouidi E, Vergoulas G, Anifanti M, Deligiannis A. A randomized controlled trial of exercise training on cardiovascular and autonomic function among renal transplant recipients. Nephrol Dial Transplant. 2013;28(5):1294-305.

118. Riess KJ, Haykowsky M, Lawrance R, Tomczak CR, Welsh R, Lewanczuk R, et al. Exercise training improves aerobic capacity, muscle strength, and quality of life in renal transplant recipients. Applied physiology, nutrition, and metabolism = Physiologie appliquee, nutrition et metabolisme. 2014 39(5):566-71.

119. Karelis AD, Hebert MJ, Rabasa-Lhoret R, Rakel A. Impact of resistance training on factors involved in the development of new-onset diabetes after transplantation in renal transplant recipients: An open randomized pilot study. Can J Diabetes. 2016;40(5):382-8. 